\title{
Justicia de género en el plano judicial. Análisis comparado sobre el derecho fundamental de la mujer a tomar decisiones sobre su propio cuerpo en contextos de violencia**
}

\section{Gender justice at the judicial level. Comparative analysis on the fundamental right of women to make decisions about their own bodies in violence contexts}

RESUMEN

$\mathrm{Al}$ ser concebidos los derechos fundamentales, desde su funcionalidad, como un sistema dinámico integrado para que las personas puedan alcanzar una vida digna, se despierta el interés general por su estudio en relación con su alcance y eficacia dentro de la sociedad. La amplitud normativa del orden constitucional refleja que el desenvolvimiento judicial es un componente estructural de gran trascendencia para el alcance material de justicia. En ese sentido, el artículo plantea una aproximación a este plano del derecho mediante el estudio de casos referidos al derecho de las mujeres a decidir sobre su propio cuerpo en contextos de violencia, a fin de constatar que el desenvolvimiento en el ámbito judicial comulga con el alcance de justicia de género; de este modo, primero, se constata el cumplimiento de estándares internacionales de derechos humanos, y segundo, se aplica la Metodología de Género para el análisis del fenómeno legal. De ello se concluye que esta potestad normativa de las mujeres requiere una ruptura de diversos para-

Docente de Derechos Humanos, Universidad Técnica Particular de Loja. Doctora en Estudios Avanzados en Derechos Humanos por la Universidad Carlos III de Madrid; maestra en Derecho por la Universidad Nacional Autónoma de México; abogada por la Universidad Técnica Particular de Loja. Forma parte del grupo de investigación Estudios sobre Constitucionalismo Latinoamericano y Derechos Humanos (ECLAD) de la UTPL (Loja, Ecuador).Contacto: xmtorres@ utpl.edu.ec ORCID: 0000-0003-4867-7742.

Recibido el 5 de junio de 2019, aprobado el 12 de junio de 2020.

Para cita el artículo: ToRres SÁNCHEZ, X. Justicia de género en el plano judicial. Análisis comparado sobre el derecho fundamental de la mujer a tomar decisiones sobre su propio cuerpo en contextos de violencia. En Revista Derecho del Estado, Universidad Externado de Colombia. N. ${ }^{\circ} 47$, septiembre-diciembre de 2020, 177-213.

DOI: https://doi.org/10.18601/01229893.n47.06 
digmas, a fin de lograr la materialidad de este derecho fundamental en los distintos componentes del sistema jurídico, en articulación con los derechos humanos y un verdadero alcance de justicia de género.

PALABRAS CLAVE

Derechos humanos, justicia, género, derechos, mujeres, violencia sexual.

SUMMARY

As fundamental rights are conceived from their functionality, as a dynamic integrated system so that people can achieve a dignified life, the general interest for their study is awakened, on aspects related to their scope and effectiveness within society. Thus, the normative breadth of the constitutional order reflects that judicial development is a structural component, of great importance for the material scope of justice. In this sense, the article proposes an approach to this level of Law, through the study of cases on the right of women to decide on their own body in contexts of violence, in order to verify that, the development in the judicial sphere, communes with the scope of gender justice; for which, first, compliance with international human rights standards is verified; and, second, the Gender Methodology is applied to analyze the legal phenomenon. From this it is concluded that this normative power of women, requires a breakdown of various paradigms, in order to achieve the materiality of this fundamental right in the different components of the legal system, in articulation with Human Rights and a true scope of gender justice.

\section{KEYWORDS}

Fundamental Rights, Gender Justice, Human Rights, Women.

SUMARIO

Introducción. 1. El derecho fundamental de la mujer a tomar decisiones sobre su propio cuerpo en el marco de una vida libre de violencia. 2. Estándares internacionales sobre violencia de género. 2.1. Estrecho vínculo entre violencia y discriminación. 2.2. Obligación de debida diligencia. 2.3. El deber de aplicar un escrutinio estricto. 3. Metodología con perspectiva de género: análisis comparado de casos. Conclusión. Referencias.

\section{INTRODUCCIÓN}

El reconocimiento de los derechos fundamentales de las mujeres es un tema de gran trascendencia, principalmente dentro del desenvolvimiento de los 
Estados democráticos, en donde estas normas prevalecen y cuentan con un amplio catálogo de principios y garantías. Los avances al respecto se distinguen desde diversos panoramas; así, por ejemplo, desde la instauración de un orden constitucional imperativo, la toma de medidas inmediatas para proteger a los sujetos, la adscripción a estándares internacionales, y la justiciabilidad perceptible en el discernimiento judicial.

De entre las aristas apuntadas se enfatiza en la justiciabilidad, de cuyo sentido integrador se ha señalado que "la evolución de la cultura jurídica de una sociedad, se traduce en la correspondiente evolución de la interpretación del Derecho por los jueces [...] que sólo podrán aplicar las leyes si éstas guardan concordancia con la Constitución [...], adoptando además criterios interculturales o plurales de interpretación"

La justicia de género, en el plano judicial, se orienta al mismo tiempo a remediar las relaciones asimétricas de poder, descomponer las estructuras de desigualdad y evidenciar la presencia de estereotipos, ya sea en las normas vigentes o en los hechos y pruebas. Desde esta perspectiva, la resolución judicial requiere una profunda comprensión sobre la desigualdad, la discriminación y la violencia, que se traduzca en una "adecuada identificación de las relaciones de poder desiguales entre los géneros, utilización de un lenguaje no sexista, ausencia de prejuicios, incorporación de estándares internacionales que protegen los derechos de las mujeres, incluyendo jurisprudencia de mecanismos internacionales" 2 .

La existencia de una cultura patriarcal generalizada y firmemente arraigada, tiende a replicar estructuras de poder y subordinación social, que acentúan para la mujer un modelo de inferioridad multinivel, que conlleva el desconocimiento de sus derechos. Dicha dominación se dispone en estructuras verticales que propician "una mezcla de violencia a la vez directa, estructural y cultural que, intimida y reprime; institucionaliza; e, interioriza, legitimando la continuidad y la reproducción de la estructura"3.

Ya en el plano judicial, tanto para el tratamiento de casos de violencia sexual como para aquellos en los que, producto de este abuso, se produjo un embarazo que derivó en la decisión por parte de la mujer de abortar, se hacen visibles obstáculos, prejuicios y discriminación, puesto que "las ideas de los jueces, fiscales y abogados sobre lo que constituye una violación, sobre cómo se prueba y sobre las actitudes correctas de las mujeres, llevan a la despena-

1 ORIAS, R. (ed.). El derecho de acceso a la justicia de mujeres. Módulo informativo para operadores judiciales y periodistas. Bolivia: Fundación Construir, 2015, 103.

2 OHCHR. Herramienta para la incorporación del enfoque de derechos humanos y la perspectiva de género en la elaboración de sentencias relativas a delitos de femicidio y otras formas de violencia contra la mujer. Oficina del Alto Comisionado de Naciones Unidas. Disponible en: https://www.ohchr.org/Documents/Issues/Women/wrGs/Herramienta_DHvSG_alta.pdf

3 Galtung, J.Paz por medios pacíficos. Paz y conflicto, desarrollo y civilización. Bilbao: BAKEAZ, 2003, 57-70. 
lización de facto de conocidos y de las violaciones en cita"4, conduciendo a la revictimización y favoreciendo la postura de condena de la mujer.

En tales circunstancias se restringen los derechos a una vida libre de violencia y a tomar decisiones sobre el propio cuerpo -impulsados por las mujeres y por los derechos humanos-, esto a pesar de tratarse de derechos fundamentales de la mujer, de carácter subjetivo y de ejercicio autónomo, y de encontrarse amparados por un marco jurídico internacional fortalecido, en virtud del cual significan para los Estados compromisos convencionales de obligatoriedad en cuanto al apoyo para su ejercicio y cumplimiento efectivos; por tanto se puede afirmar que "no basta la titularidad de los derechos [...] si no existen condiciones sociales de acceso a ellos" ${ }^{\text {, }}$ es decir, un equilibrio entre bienestar social y ejercicio autónomo.

De ahí que se incursione en el análisis de los criterios judiciales aplicados en casos sobre vulneración de derechos fundamentales de la mujer, con el objeto de constatar la evolución jurídico-social respecto del alcance de la justicia de género; para lo cual se han seleccionado sucesos acontecidos en cuatro países que forman parte de la Comunidad Andina de Naciones, a saber, Perú, Colombia, Ecuador y Bolivia, en los cuales se destacan dos características relevantes comunes: primero, a partir de los años noventa se adscriben a la tendencia latinoamericana sobre la introducción de cambios importantes a nivel de su normativa constitucional ${ }^{6}$, lo que refiere una amplitud normativa de garantía de derechos. Segundo, la pertenencia de estos países al Sistema Interamericano de Derechos Humanos, desde donde se definen claros compromisos de promoción y vigencia de normas fundamentales, "cuya expansión crea un nuevo espacio legal discursivo de la arena global [...] que define que el derecho internacional tiene competencia sobre asuntos anteriormente considerados dentro de la responsabilidad doméstica de los Estados"7. Es por ello que se toma como punto de partida la verificación del cumplimiento de estándares establecidos dentro del Sistema Interamericano, dada la suscripción de instrumentos internacionales y disposición normativa por parte de los países antes mencionados.

4 Jaramillo, I. La crítica feminista al derecho. En Ávila, R.; SALGado, J. y VAlladARES, L. (comps.), El género en el derecho. Ensayos críticos. Quito: Ministerio de Justicia y Derechos Humanos, 2009, 122.

5 LAMAS, M. Algunas reflexiones relativas al derecho a decidir sobre el propio cuerpo. En Astelarra, J. (coord.), Género y cohesión social. Madrid: Fundación Carolina-Ce ALCI, 2007, 51.

6 UPRIMNY, R. Las transformaciones constitucionales recientes en América Latina: tendencias y desafíos. En Rodríguez, C. (coord.), Un mapa para el pensamiento jurídico del siglo XXI. Buenos Aires: Siglo XXI Editores, 2011, 109-138.

7 Merry, S. Las mujeres, la violencia y el sistema de Derechos Humanos. En La Ventana, 2002, 15, 66. Disponible en: https://dialnet.unirioja.es/servlet/articulo?codigo $=5202242$ [fecha de consulta: 11 de mayo de 2020]. 
Más adelante, se aplica la Metodología de Género para el análisis del fenómeno legal, que señala la existencia de tres componentes del sistema jurídico: sustantivo, en donde se ubican las leyes positivas; estructural, integrado tanto por las instituciones que crean, interpretan y aplican el derecho, como por el contenido que de ello se deriva; y político-cultural, conformado por la aplicación de la ley mediante costumbres, que son definidas por el significado que los individuos tienen respecto de su aplicación ${ }^{8}$.

En el análisis comparado, se toma posición en el plano estructural, en donde se ubican los casos judicializados que dotan de significado a las normas, limitando o restringiendo su contenido, de cara a los demás componentes del sistema jurídico antes señalado. Con ese fin, se aplican cuatro pasos de este método, para identificar en el caso analizado, una vasta comprensión sobre el fenómeno de la violencia por parte del ente judicial, conciencia sobre las relaciones de poder, uso de lenguaje no sexista, factores de discriminación, que pudieran haber influido en la decisión ${ }^{9}$, es decir, elementos que reflejen el alcance de justicia de género.

1. EL DERECHO FUNDAMENTAL DE LA MUJER A TOMAR DECISIONES SOBRE SU PROPIO CUERPO EN EL MARCO DE UNA VIDA LIBRE DE VIOLENCIA

Las corrientes filosóficas que componen la teoría de género brindan aportes conceptuales para denunciar estructuras de desigualdad; sus enfoques han permitido revelar que a la mujer se le atribuyó una categoría distinta, una especie de sitial negativo frente al estatus masculino; de ahí que se haya llegado a "cuestionar los fundamentos mismos y la presunta neutralidad del discurso racional" 10 , lo cual deja entrever que la diferencia sexual es un modo de legitimación del poder y una categoría política.

Posturas radicales de esta teoría afirman que "la sexualidad es al feminismo lo que el trabajo al marxismo" 11 ; en este sentido, se denuncia la existencia de una teoría del poder en donde el hombre y la mujer son creados para la dominación y la sumisión, y el espacio en donde corresponde su desenvolvimiento es lo público y privado, respectivamente.

Desde el aporte crítico feminista no solo se llegan a evidenciar las problemáticas sociales, sino que también se activa el accionar social, cuya contribución "ha sido llevar al espacio público temas que se han considerado exclusivos del

8 FACio, A. Cuando el género suena cambios trae (una metodología para el análisis de género del fenómeno legal). San José: ILANUD, Programa Mujer, Justicia y Género, 1992, 63-64.

9 OHCHR. Herramienta para la incorporación del enfoque de derechos humanos y la perspectiva de género en la elaboración de sentencias relativas a delitos de femicidio y otras formas de violencia contra la mujer, cit.

10 Braidotti, R. Feminismo, diferencia sexual y subjetividad nómade. Barcelona: Gedisa, 2004, 14 .

11 MacKinnon, C. Hacia una teoría feminista del Estado. Madrid: Cátedra, 1995, 23. 
espacio privado -aborto, violencia doméstica-, ensanchando de este modo el ámbito de la política" ${ }^{12}$; de esa manera, los espacios asignados a lo femenino y lo masculino se mezclan y se diluyen en el entramado social, favoreciendo la idea de una movilidad de los sujetos ${ }^{13}$ para el desenvolvimiento y atención de sus diversas necesidades.

En este contexto, la exigibilidad de la acción política femenina, aunada al desarrollo del derecho internacional de los derechos humanos, ha transformado el panorama; como muestra de ello, la violencia contra las mujeres que "no es generalmente perpetrada por los Estados sino por ciudadanos privados. Sin embargo, las activistas argumentaron que la negativa del Estado a proteger a las mujeres de la violencia, es en sí misma una violación a los derechos humanos"14.

De ahí que, de manera progresiva, se han configurado instrumentos jurídicos como la Convención Interamericana para Prevenir, Sancionar y Erradicar la Violencia contra las Mujeres (1994), que reconoce el derecho de toda mujer a una vida libre de violencia, en la vida pública y privada, identificándose tres tipos de violencia: física, sexual y psicológica; el mismo documento compromete a los Estados a adoptar medidas para prevenir, sancionar y erradicar este problema ${ }^{15}$.

Las relatoras especiales de la onU sobre los derechos de las mujeres han expresado que la protección de las normas internacionales de los derechos humanos y los Estados "protegen a las mujeres de la violencia y la discriminación por parte de entidades privadas no estatales [...], cualquier persona, organización o empresa; y, están obligados a actuar con la diligencia debida para erradicarla" ${ }^{16}$.

Por su parte, la Convención para la Eliminación de Todas las Formas de Discriminación contra la Mujer (1979) no reconoce de manera explícita el derecho a una vida libre de violencia; sin embargo, el comité encargado de velar por su cumplimiento incluyó en el año 1992 una aclaración en el sentido de que la discriminación "incluye la violencia dirigida contra la mujer porque es mujer o que le afecta de manera desproporcionada, y que

12 Carosio, A. Feminismo y cambio social en América Latina y el Caribe. En Valdivieso, M. et al.,Feminismo y cambio social en América Latina y el Caribe. Buenos Aires: ClACso, 2012, 13.

13 Delgado de Smith, Y. El sujeto: los espacios públicos y privados desde el género. En Revista de Estudios Culturales, 2008, 1, 2, 113-126. Disponible en: https://dialnet.unirioja.es/ servlet/articulo?codigo $=3987106$

14 Merry. Las mujeres, la violencia y el sistema de derechos humanos, cit.

15 OEA. Convención Interamericana para Prevenir, Sancionar y Erradicar la Violencia contra la Mujer, Belem do Pará, arts. 1, 2, 3 y 7. Disponible en: https://www.oas.org/es/mesecvi/ docs/BelemDoPara-ESPANOL.pdf

16 CIDH. Declaración Conjunta de las Relatoras Especiales sobre los Derechos de la Mujer. Disponible en: https://www.cidh.oas.org/declaracion.mujer.htm 
[...] puede contravenir disposiciones de la convención, sin tener en cuenta si hablan expresamente de violencia" ${ }^{17}$.

Sobre la violencia doméstica, la Comisión de Derechos Humanos de la ONU ha manifestado que sus formas "tienen lugar en el contexto de la discriminación de jure y de facto contra la mujer y de la condición asignada a la mujer en la sociedad, y se ven agravadas con los obstáculos con que suelen enfrentarse las mujeres al tratar de obtener una reparación del Estado"18.

Dentro de esta tendencia de evolución jurídica de los derechos humanos se han consolidado otros espacios y documentos que fortalecen el marco normativo internacional de protección de las mujeres frente a la violencia, y que establecen compromisos para que los Estados disminuyan o erradiquen esta problemática; entre ellos se destacan la Conferencia Mundial del Año Internacional de la Mujer (1974); los Principios de El Cairo-Arusha (2002); las conferencias de Copenhague (2009), Nairobi (2006), Viena (1993) -en donde se expide la Resolución 40/36- y Beiging (1995) -con su plataforma de acción-; la Resolución 1325 del Consejo de Seguridad sobre la Mujer, la Paz y la Seguridad (2000); la Resolución 61/143 de la Asamblea General de las Naciones Unidas (2006); la Campaña para poner fin a la violencia contra las mujeres (2008), y la creación de onU Mujeres (2011).

A pesar de esta tendencia de protección hacia la mujer y de que la gran mayoría de países se adscriben a este marco jurídico internacional, admitiendo que este problema no es un asunto privado, sino de carácter público, que requiere de esfuerzos gubernamentales para su eliminación, la realidad de las estadísticas refleja que el fenómeno de la violencia persiste, y ha llegado a constituirse en una problemática mundial generalizada difícil de erradicar ${ }^{19}$, "ya que está amparada socialmente, porque aún el poder económico, político, doméstico y mediático lo tienen los hombres y obtienen privilegios de ello"20.

De las formas de violencia reconocidas, la de tipo sexual es quizá la conducta más perversa, tanto por su significado como por el hecho de que ni su perpetrador, ni el escenario en donde se ejerce, distinguen una vía de aplicación única; de ahí que el agresor puede ser la pareja, los familiares,

17 CEDAW. Recomendación General n. ${ }^{\circ} 19$ adoptada por el Comité para la Eliminación de la Discriminación contra la Mujer. Disponible en: https://tbinternet.ohchr.org/Treaties/CEDAw/ Shared\%20Documents/1_Global/INT_CEDAW_GEC_3731_S.pdf

18 ACNUR. Resolución de la Comisión de Derechos Humanos 2003/45. Disponible en: https://www.acnur.org/fileadmin/Documentos/BDL/2005/3203.pdf?view=1

19 Según las estadísticas publicadas por la oms en 2017, alrededor de una de cada tres mujeres en el mundo ha sufrido violencia física y/o sexual de pareja o de terceros a lo largo de su vida. oms. Violencia contra la mujer. Disponible en: https://www.who.int/es/news-room/ fact-sheets/detail/violence-against-women

20 Hernández, I. Principio de igualdad y violencia de género. En Cuesta, V. y Santana, D. (eds.), Estado de derecho y discriminación por razón de género, orientación e identidad sexual. España: Aranzadi, 2014, 195. 
personas allegadas, figuras de autoridad, explotadores, prácticas tradicionales, e incluso grupos estatales y rebeldes durante conflictos armados.

Al respecto, el derecho internacional humanitario y, más adelante, el derecho internacional de los derechos humanos han puesto en evidencia el problema de la violencia sexual, estableciendo su prohibición en documentos jurídicos como las Convenciones de Ginebra (1949) y su Protocolo II (1977), o el Estatuto del Tribunal Penal Internacional para Ruanda (1998), los cuales han denotado el simbolismo de dicho acto, en cuanto a que "el cuerpo de la mujer, que se considera propiedad del hombre y por defecto de la comunidad o del Estado, se instrumentaliza para transmitir mensajes de poder al enemigo" 21 . Desde la perspectiva de la mujer como propiedad del hombre y del Estado, la violencia sexual sigue siendo un daño que afecta a un titular masculino, que cree tener derecho sobre el cuerpo y la sexualidad femenina, lo cual limita en la mujer, el hecho de convertirse en sujeto activo ante dicha opresión.

Es solo a partir de las últimas décadas que, con las exigencias feministas y los avances en materia de derechos humanos, en gran parte de países, se ha llegado a conceptualizar este delito desde el punto de vista femenino, como un problema que coarta la libertad de la mujer, somete su voluntad y violenta un espacio tan íntimo como su propio cuerpo, dejando en quien lo experimenta daños psicológicos en su autoestima, desconfianza y sentido de falta de protección, además de causar secuelas físicas graves, y consecuencias biológicas de compleja reparación ${ }^{22}$.

En el fenómeno de la violencia sexual, mucho más allá del mito respecto de que el agresor es motivado por instintos meramente sexuales, se encuentra aquel que lo ubica como un ser desconocido para la víctima; en contraposición, otros estudios señalan que la motivación es sicológica, y que además del considerable número de perpetradores desconocidos, operan sujetos conocidos de la persona que es agredida ${ }^{23}$.

Los delitos por violencia sexual tienen significado y transmiten al cuerpo de la mujer un mensaje según el cual su "destino es ser contenida, censurada, disciplinada, reducida" 24 en términos de la moral social; desde el punto de vista biológico, conllevan consecuencias reproductivas específicas, cuyas

21 Vañó, R. La violencia sexual como crimen de genocidio. Reflexiones en clave de género a propósito del caso Akayesu (Tribunal Penal Internacional para Ruanda). En Revenga, M. y GARCía, C. (coords.), Decisiones básicas en materia de violaciones de derechos humanos. Madrid: Centro de Estudios Políticos y Constitucionales, 2015, 25, 169.

22 AResti, L. La violencia impune. Una mirada sobre la violencia sexual contra la mujer. México: Universidad Autónoma de Nuevo León, 1997, 39-49.

23 Violencia sexual en Latinoamérica y el Caribe: análisis de datos. Disponible en: https:// clacaidigital.info/handle/123456789/980

24 Segato, R. La escritura en el cuerpo de las mujeres asesinadas en Ciudad Juárez. Buenos Aires: Tinta Limón, 2013, 23. 
regulaciones legales, en su gran mayoría, se anticipan, imponiendo el deber femenino de reproducción y dejando desprovista a la mujer de su potestad de aceptar o no un embarazo producto de una violación llena de simbolismo $\mathrm{y}$ afectaciones sobre su propio ser.

Se retoma aquí el dilema político sobre si el derecho a decidir corresponde al ámbito público o privado, es decir, sobre "qué decisiones de los ciudadanos atañen a su exclusiva competencia, aunque también requieran apoyo del Estado" 25 . En el debate convergen posturas culturales, religiosas, morales, científicas, políticas y económicas, con la estructura jurídica internacional de derechos humanos, en donde se retoman los derechos básicos de igualdad, libertad y la vida, como fundamentos de la humanidad y principios de obligatorio cumplimiento por parte del Estado.

En este contexto, el derecho a decidir sobre el propio cuerpo abarca una multiplicidad de ámbitos que involucran la libertad autónoma de la persona sobre su ser corporal, por lo que su ejercicio resultaría básico; sin embargo, "cada sociedad elabora simbólicamente su concepción del cuerpo [...] que está en el centro de la vida relacional y política, en el centro del simbolismo social, igualmente está en el imaginario de la actividad psíquica individual”26; por lo tanto, lo corporal emite mensajes en donde se inscriben sexo, etnia y clase. Además, el cuerpo también es visto como mercancía que se asocia a aspectos positivos -juventud, salud, belleza- y a aspectos negativos -tráfico sexual, esclavitud $-^{27}$, lo que dificulta la obtención de una respuesta única respecto del derecho a decidir sobre el propio cuerpo, que sea de carácter universal, ética y justa.

Jurídicamente, el derecho de la mujer a tomar la decisión de interrumpir la vida que lleva en su propio cuerpo puede derivarse de múltiples circunstancias, de las se subraya el haber sido víctima de violencia de tipo sexual, lo que, como se señaló antes, puede acontecer en diversos escenarios. Esto contrapone tres derechos básicos universalmente aceptados, que suponen una de las exigibilidades feministas que más polos opuestos dispone.

La capacidad de reproducción es una característica exclusiva de la mujer, y esto conduce a plantearse la pregunta sobre si "existen derechos fundamentales de las mujeres y sólo de las mujeres" ${ }^{28}$; en este contexto, es posible afirmar que sí existe un derecho fundamental propio de la mujer, que es precisamente la autoderminación en materia de maternidad o de la toma de decisiones sobre su propio cuerpo; y lo es porque "forma un todo con la libertad personal, que comporta la autodeterminación de la mujer; porque

\footnotetext{
25 Lamas. Algunas reflexiones relativas al derecho a decidir sobre el propio cuerpo, cit., 48

26 Ibíd., 43.

27 Ibíd., 44.

28 Ferrajoli, L. Derechos y garantías: la ley del más débil. Madrid: Trotta, 2006, 84.
} 
cualquier decisión heterónoma equivale a una lesión [...] de ser tratada como mero instrumento para fines no propios; porque su prohibición penal, equivale a una obligación" 29 .

En cada una de estas razones se encuentra implícito el sentido de fundamentalidad de este derecho; de tal manera, primero, existe una articulación directa del derecho con la libertad negativa de la mujer a no ser madre, ya que esta decisión es precisamente una autoderminación sobre sí misma; segundo, solamente la mujer puede decidir al respecto, por cuanto solamente ella es quien compromete su cuerpo para ser madre; tercero, la prohibición de la toma de decisión autónoma equivale a imponer otras responsabilidades conexas a la maternidad: de alimentación, de cuidado, etc.

La penalización de este derecho fundamental de la mujer pone en evidencia cómo desde la perspectiva androcentrista se ha definido una obligación de desenvolvimiento específico de las mujeres articulado a la maternidad, en donde el hombre también ha decidido por ella, ya que " sólo desvalorizando a éstas como personas y reduciéndolas a instrumentos de procreación es como los varones han podido expropiarlas de ésa su personal potencia sometiéndola al control penal" ${ }^{\prime 30}$.

Al respecto, en el orden mundial prevalecen tres posturas legales: por una parte, se encuentran aquellos países que han liberalizado completamente sus leyes, dando prioridad al derecho femenino -Canadá, Cuba, Puerto Rico, Corea del Norte, China, Bélgica, Francia, Alemania, Grecia, Rusia, México, Cabo Verde-; por otro lado, se encuentran una gran mayoría de países que acogen el derecho de la mujer de manera parcial, bajo ciertas circunstancias que, cuando no concurren, conllevan una sanción penal -Irlanda, Andorra, San Marino, Francia, Alemania, Grecia, Rusia, Brasil, Costa Rica, Chile, Colombia, Ecuador, Argentina, Venezuela-; finalmente, se encuentra la postura en la que prevalece el derecho a la vida del feto, a costa de sanciones penales en caso de incumplimiento -República Dominicana, El Salvador, Nicaragua, Ciudad del Vaticano y Malta- ${ }^{31}$.

Esta realidad tiene ciertos matices, ya que en países en donde el aborto es prohibido, o aun si se permite bajo ciertas circunstancias, las estadísticas muestran altos índices de mortalidad materna, lo cual se debe a que quienes recurren al procedimiento por temor a verse judicialmente castigadas deben hacerlo en la clandestinidad y bajo condiciones insalubres, lo que pone en riesgo o termina con su vida. Así por ejemplo, según información difundida por Human Rights Watch en 2013, en Ecuador "la prohibición generalizada del aborto contribuye a la mortalidad y morbilidad materna"; de tal manera, "las

29 Ibíd., 85.

30 Ibíd., 86.

31 El Universal. Disponible en: https://www.eluniversal.com.mx/articulo/periodismo-dedatos/2015/10/10/58-paises-permiten-interrupcion-legal-del-embarazo-sin 
cifras sobre el índice de mortalidad materna por la práctica de aborto incluso en casos de violación, habían aumentado en más del doble para 2011, con 105 muertes maternas cada 100.000 nacimientos con vida respecto de 2006 " 32 .

En este panorama teórico, legislativo, crítico y social, con independencia de la existencia normativa de apertura o no en cuanto al derecho fundamental de la mujer a decidir sobre su propio cuerpo en el marco de una vida libre de violencia, en el ámbito judicial se requiere que los tribunales se despojen de criterios sexistas estereotipados y discriminatorios, y que "tomen en cuenta las necesidades concretas que enfrentan sujetos con cuerpos sexuados, cuerpos viejos, enfermos o con discapacidades, para poder decidir" 33 .

\section{ESTÁNDARES INTERNACIONALES SOBRE VIOLENCIA DE GÉNERO}

En el vertiginoso crecimiento de las sociedades democráticas latinoamericanas, que han dado el salto del estado de legalidad al estado de derechos, se disponen formas de justicia constitucional para lograr la eficacia material y hacer que los derechos se cumplan ${ }^{34}$. En este sentido, es posible identificar avances importantes, según los cuales se establecen "nuevos ámbitos de interés y de acción social para demandar e impulsar procesos [...] que girarán en torno a diversidades de género, generacionales, étnicas, nacionales, junto al impulso integral de los derechos" 35 .

En este escenario, al interior de los Estados se produce una apertura de cara al derecho internacional de los derechos humanos, en virtud de que la ratificación de instrumentos del sistema convencional requiere el asumir varios compromisos, de entre los que se destaca aquel por el cual los jueces deben "contrastar las normas generales internas, frente a las normas del sistema convencional internacional [...], deberán desarrollar una serie de razonamientos que permitan la aplicación más amplia posible y el mayor respeto a las obligaciones establecidas por los tratados internacionales" ${ }^{\prime 36}$.

32 Human Rights Watch. Ecuador: se niega a víctimas de violación sexual la posibilidad de abortos seguros y lícitos. Washington D.C.: Human Rights Watch, 2013. Disponible en: https:// www.hrw.org/es/news/2013/08/23/ecuador-se-niega-victimas-de-violacion-sexual-la-posibilidadde-abortos-seguros-y

33 LAMAS. Algunas reflexiones relativas al derecho a decidir sobre el propio cuerpo, cit., 50 .

34 UPRIMNY. Las transformaciones constitucionales recientes en América Latina: tendencias y desafios, cit., 124.

35 Duque, C.; Chávez, G. y Melo, M. Experiencias en Ecuador: retorno a la democracia y avances en derechos humanos. En Programa Andino de Derechos Humanos (comp.), Defensa de los derechos humanos en América Latina. Avances y retrocesos. Quito: Abya-Yala, 2009, 315-428.

36 CARBonel, M. Introducción al control de convencionalidad, 71. Disponible en: https:// www.academia.edu/download/2021959/El_control_de_convencionalidad_y_el_sistema_colombiano.pdf 
De lo antes señalado, en cuanto a la violencia contra la mujer, cabe decir que "aunque los individuos no son legalmente responsables bajo la ley internacional de derechos humanos, los Estados son responsables por no cumplir sus obligaciones, incluso por actos de personas privadas, si no hacen un esfuerzo por eliminar o mitigar tales actos" ${ }^{\prime 37}$; por tal motivo, al ser los jueces funcionarios estatales, mediante su accionar pueden contribuir a mitigar tales actos, acogiendo estándares que nutran sus resoluciones con enfoque de género, en cumplimiento de la responsabilidad internacional de convencionalidad.

El desarrollo de estándares en el marco de los sistemas supranacionales de derechos humanos tiene sus bases principalmente en "los pronunciamientos de la Corte y de la Comisión Interamericana de Derechos Humanos; los informes presentados por parte de los Estados y miembros de la sociedad civil; y, desde estudios temáticos desarrollados por aquellos entes especializados"38. Sobre dicho sustento, se revisan a continuación tres estándares de derechos fundamentales de las mujeres derivados de la jurisprudencia del Sistema Interamericano.

\subsection{Estrecho vínculo entre violencia y discriminación}

La violencia es una forma de discriminación que coarta los derechos femeninos como resultado de un "orden de dominación de lo masculino y las relaciones desiguales de poder entre hombres y mujeres" 39 , orden que perjudica a estas por el hecho mismo de ser mujeres, o bien las afecta de forma desproporcionada ${ }^{40}$. Sin embargo, se ha señalado que los Estados "no siempre reflejaban de manera apropiada la estrecha vinculación entre la discriminación contra la mujer, la violencia y las violaciones de los derechos humanos y libertades" ${ }^{41}$

Varios han sido los casos, sometidos a conocimiento de la Corte Interamericana, que han conducido a la construcción de este estándar, de entre los cuales se enfatiza en aquellos relacionados con eventos de violencia física y sexual, tales como González y otras vs. México, I.V. vs. Bolivia, Rosendo Cantú y otra vs. México, López Soto vs. Venezuela. En estos se ha manifestado que la violencia sexual "afecta desproporcionadamente a las mujeres,

37 MERry. Las mujeres, la violencia y el sistema de derechos humanos, cit.

38 CIDH. Estándares jurídicos vinculados a la igualdad de género y a los derechos de las mujeres en el sistema interamericano de derechos humanos: desarrollo y aplicación. Actualización del 2011-2014. Bolivia: Fundación Construir, 2015, 19. Disponible en: http://www.oas.org/es/ cidh/informes/pdfs/EstandaresJuridicos.pdf

39 DuQue, ChÁvez y Melo. Experiencias en Ecuador: retorno a la democracia y avances en derechos humanos, cit., 315-428.

40 CEDAw. Recomendación General n. ${ }^{\circ} 19$ adoptada por el Comité para la Eliminación de la Discriminación contra la Mujer, cit.

41 Ibíd. 
en tanto exacerba las relaciones de subordinación y dominación históricamente persistentes entre hombres y mujeres, es por ello que constituye una manifestación de la discriminación contra la mujer" ${ }^{42}$.

En dichos casos se ha señalado, por ejemplo, que los problemas sobre violencia y discriminación ponen de manifiesto la "existencia de una limitación, anulación y restricción histórica del derecho a la libertad y autonomía de la mujer, en su salud sexual y reproductiva, [...] dada la asignación de un rol superior al hombre, para decidir sobre el cuerpo femenino" ${ }^{43}$, por considerarlas "incapaces de tomar decisiones de forma responsable" 44 .

Desde esta perspectiva, la definición del estándar instruye al Estado en cuanto a que la violencia contra la mujer, además de constituirse en discriminación, deniega sus derechos humanos y coarta sus libertades, con lo cual se orienta a fortalecer los mecanismos estatales para contrarrestarla, instruyéndose al aparato judicial para la emisión de resoluciones acordes con este criterio.

\subsection{Obligación de debida diligencia}

Son múltiples las cuestiones que para un Estado abarca la obligación de debida diligencia, para prevenir, investigar y sancionar la violencia contra las mujeres, las que se derivan principalmente de la Convención para la Eliminación de Todas las Formas de Discriminación contra la Mujer ${ }^{45}$ y de la Convención de Belem do Pará (1995). Esta obligación se sintetiza como un deber relacionado con el "cuidado objetivo de proceder o conducirse de forma tal que se busque llevar a efecto, real y concretamente, aquello que corresponde ser cumplido" 46 .

Este deber conlleva para los actores públicos un cuidado objetivo en sus conductas y actitudes; sin embargo, son precisamente los funcionarios involucrados en la sanción quienes contradicen este deber, actuando de manera discriminatoria, al emitir, por ejemplo, juicios de valor que revictimizan a las mujeres agredidas, lo que deriva en diligencias tardías, inadecuado desenvolvimiento judicial e impunidad de los actos.

42 Corte IDH. Caso López Soto y otros vs. Venezuela. Excepciones Preliminares, Fondo, Reparaciones y Costas. Sentencia del 26 de septiembre 2018, 61. Disponible en: https://www. corteidh.or.cr/docs/casos/articulos/seriec_362_esp.pdf

43 Corte IDH. Caso I.V. vs. Bolivia. Excepciones Preliminares, Fondo, Reparaciones y Costas. Sentencia del 30 de noviembre de 2016. Disponible en:http://www.corteidh.or.cr/docs/ casos/articulos/seriec_329_esp.pdf

44 Ibíd., 48.

45 CEDAw. Recomendación General n. ${ }^{\circ} 19$ adoptada por el Comité para la Eliminación de la Discriminación contra la Mujer, cit.

46 Red de Defensorías de mujeres de la Federación Iberoamericana del Ombudsman. Debida diligencia en el acceso a la justicia y tutela judicial efectiva de las mujeres víctimas de violencia familiar: alcances, limitaciones y propuestas, 26. Disponible en: http://www.portalfio. org/wp-content/uploads/2015/07/FIO.INF_.0023.2015.pdf 
En este sentido, la Corte Interamericana se ha pronunciado claramente, para resaltar la responsabilidad de una actuación diligente del Estado frente a casos como Penal Castro vs. Perú, Veliz Franco y otros vs. Guatemala, Masacre de las Dos Erres vs. Guatemala, Atenco vs. México, en los que se ha manifestado que "la falta de debida diligencia y la tolerancia por parte de los tribunales al momento de tramitar, así como la falta de tutela judicial efectiva, $[\ldots]$ han permitido el perjuicio de los derechos de las víctimas" ${ }^{\prime 4}$.

De igual manera, en casos de violencia sexual la Corte Interamericana ha manifestado que la debida diligencia comporta, entre otros aspectos, asistencia jurídica sin dilaciones, puesto que "si el paso del tiempo incide de manera relevante en la situación jurídica del individuo, resultará necesario que el procedimiento avance con mayor diligencia a fin de que se resuelva en tiempo breve" 48 .

El estándar sobre debida diligencia se refuerza con lo manifestado por este Tribunal cuando señala que "el derecho de acceso a la justicia implica que la solución de la controversia se produzca en tiempo razonable, ya que la demora prolongada puede llegar a constituir, por sí misma, una violación de las garantías judiciales" ${ }^{49}$.

\subsection{El deber de aplicar un escrutinio estricto}

De acuerdo con este estándar, se señala para los órganos estatales, entre ellos los entes judiciales, la obligación estricta de constatar leyes, normas, prácticas y políticas que establezcan un trato diferenciado basado en el sexo, cuya aplicación pudiera tener un impacto discriminatorio. De tal manera, la Corte Interamericana, en el caso Atala Riffo y niñas $v$ s. Chile, ha señalado "la necesidad de aplicar un escrutinio mayor cuando la decisión judicial se relacione con el derecho a la igualdad de grupos poblacionales tradicionalmente discriminados" $" 50$.

De igual manera, en el caso Fernández Ortega y otros vs. México ${ }^{51}$ ha afirmado que "en casos de violencia contra la mujer, ciertos instrumentos

47 Corte IDH. Caso de la masacre de las Dos Erres vs. Guatemala. Excepción Preliminar, Fondo, Reparaciones y Costas. Sentencia del 24 de noviembre de 2009,37. Disponible en: http:// www.corteidh.or.cr/cf/jurisprudencia2/ficha_tecnica.cfm?nId_Ficha=361\&lang=es

48 Corte IDH. Caso de mujeres víctimas de tortura sexual en Atenco vs. México. Excepciones Preliminares, Fondo y Reparaciones. Sentencia del 28 de noviembre de 2018, 144. Disponible en: https://www.corteidh.or.cr/docs/casos/articulos/seriec_371_esp.pdf

49 Corte IDH. Caso de la masacre de las Dos Erres vs. Guatemala, cit.

50 Corte IDH. Caso Atala Riffo y niñas vs. Chile. Excepción Preliminar, Fondo, Reparaciones y Costas. Sentencia del 24 de febrero de 2012, 44. Disponible en: https://corteidh.or.cr/ docs/casos/articulos/seriec_239_esp.pdf

51 Corte idH. Caso Fernández Ortega y otros vs. México. Excepción Preliminar, Fondo, Reparaciones y Costas. Sentencia del 30 de agosto de 2010. Disponible en: http://www.corteidh. or.cr/cf/jurisprudencia2/ficha_tecnica.cfm?nId_Ficha=338\&lang=es 
internacionales resultan útiles para precisar y dar contenido a la obligación estatal reforzada de investigarlos con la debida diligencia" ${ }^{52}$. Y en idéntico sentido se ha manifestado la Corte en Rosendo Cantú y otros vs. México ${ }^{53}$.

De esta forma, el deber de los Estados de aplicar un estricto escrutinio o análisis cabal de instrumentos jurídicos del derecho internacional de los derechos humanos, para resolver casos en donde se vulneren derechos fundamentales de la mujer, conduce a fortalecer la toma de decisiones judiciales y favorecer la equidad, lo cual se traduce en la vigencia de derechos desde perspectivas consolidadas, para el alcance de la justicia de género.

\section{METODOLOGÍA CON PERSPECTIVA DE GÉNERO:}

ANÁLISIS COMPARADO DE CASOS

Tomando en cuenta el papel trascendental e integrador que asumen quienes aplican el derecho, el análisis comparado que se dispone se articula con la constatación del alcance de justicia de género, respecto de los derechos de la mujer a tomar decisiones sobre su propio cuerpo en el marco de una vida libre de violencia sexual, bajo el supuesto de la presencia de un sistema jurídico consolidado en cuatro países latinoamericanos -Ecuador, Colombia, Perú y Bolivia- que se adscriben a la postura neoconstitucionalista y al sistema convencional de los derechos humanos ${ }^{54}$.

Tales características suponen la disposición de elementos adecuados para propiciar una valoración justa, indistintamente del nivel judicial en donde aplican, ya que se dota a los jueces de independencia judicial y se reconocen derechos fundamentales y sociales, además de disponerse una articulación al derecho internacional de los derechos humanos. Tales transformaciones fortalecen los Estados de derecho, dotándolos de un carácter aspiracional ${ }^{55}$; incluso, la norma constitucional ecuatoriana y la boliviana asumen posturas de apertura al pluralismo jurídico e intercultural, que se inscriben en un modelo neoconstitucionalista andino ${ }^{56}$.

Dada la adscripción de tales países al modelo neoconstitucionalista, como un escenario propicio para el ejercicio de derechos fundamentales de las mujeres, en el análisis de casos se pretende verificar la aplicación de estándares internacionales que emanan del Sistema Interamericano; al tiempo

52 Ibíd.

53 Corte IDH. Caso Rosendo Cantú y otra vs. México. Excepción Preliminar, Fondo, Reparaciones y Costas. Sentencia del 30 de agosto de 2010,63. Disponible en: http://www.corteidh. or.cr/docs/casos/articulos/seriec_216_esp.pdf

54 UPRIMNY. Las transformaciones constitucionales recientes en América Latina: tendencias y desafios, cit., 109-138.

55 Ibíd.

56 ÁvILA, R. El neoconstitucionalismo andino. Quito: Universidad Andina Simón Bolívar, 2016. 
que se aplica la metodología para el análisis de género del fenómeno legal, desarrollada por Alda Facio, que permite poner en evidencia categorías no sexistas, empleando para el efecto "un análisis crítico de cómo los juristas androcéntricos han conceptualizado el fenómeno jurídico" ${ }^{57}$, lo que permite rescatar la perspectiva desde el punto de vista de los derechos de la mujer respecto de hechos que han sido sometidos a escrutinio judicial.

La selección de casos en cada país responde a que en ellos confluyen tres factores comunes: primero, versan sobre la toma de la decisión personal de abortar o no, en contextos en donde la mujer ha sido víctima de violencia física o sexual; segundo, en tales países se maneja una postura normativa sobre penalización del aborto, es decir, se permite su realización cuando concurren ciertas circunstancias; $y$, tercero, pese a tales disposiciones la mujer es criminalizada.

De acuerdo a la metodología para el análisis de género, el sistema jurídico cuenta con tres componentes -sustantivo, estructural y político cultural-, y en cada uno de ellos se disponen leyes que se influyen, limitan y definen mutuamente. Dichas leyes se validan en cada componente, si se cumplen ciertas condiciones; así, "en el sustantivo deben estar formalmente promulgadas, [...] en el estructural, emanan del contenido que les den las instituciones, [...] en el político-cultural, $[\ldots]$ la gente cree que existen y por tanto obedece" ${ }^{58}$; bajo esta perspectiva, un derecho no es tal si solamente se contempla en uno de los tres ámbitos.

Para el análisis comparado se toma posición en el plano estructural y se aplican en cada caso cuatro pasos de la metodología de género antes indica$\mathrm{da}^{59}$, a saber: primero, toma de conciencia sobre la subordinación del género femenino al masculino, lo que conduce a sospechar de la neutralidad de las instituciones jurídicas, para comprender las diferencias de la realidad y tratar de transformarlas; segundo, profundización de la comprensión del sexismo como un fenómeno que se manifiesta de diversas formas ${ }^{60}$; tercero, identificación de la mujer contemplada como el otro y asunción de que no todas

57 FAcio. Cuando el género suena cambios trae (una metodología para el análisis de género del fenómeno legal), cit., 63-64, 11.

58 Ibid., 65.

59 OHRCHR. Herramienta para la incorporación del enfoque de derechos humanos y la perspectiva de género en la elaboración de sentencias relativas a delitos de femicidio y otras formas de violencia contra la mujer, cit.

60 Son distintas formas en que el sexismo se puede manifestar, son generalizadas e internalizadas, denotan discriminación, parámetros, roles, juicios de valor, espacios predeterminados, etc. Entre las más frecuentes se destacan: androcentrismo, sobregeneralización o sobreespecificación, insensibilidad al género, doble parámetro, deber ser de cada sexo, dicotomismo sexual, familismo. Cfr. EICHLER, M. Feminist Methodology. En Current Sociology, 45, 2, 9-36. Disponible en: http://journals.sagepub.com/doi/metrics/10.1177/001139297045002003\#articleCitationDow nloadContainer [fecha de consulta: 30 de abril de 2020]. 
las mujeres son iguales; y cuarto, análisis de la situación con relación a los otros dos componentes, para poder determinar su influencia o limitación ${ }^{61}$.

\section{A. Sentencia T-988/07, Colombia}

- Antecedentes

El proceso aborda el caso de una joven de 24 años de edad, en adelante denominada вв, diagnosticada con retardo psico-motor severo y epilepsia, quien fue víctima de acceso carnal no consentido que le produjo un embarazo el cual, al momento de serle diagnosticado mediante exámenes, tenía 9 semanas de desarrollo. El aparente agresor, Xx, de 31 años de edad, de acuerdo a lo manifestado por AA, la madre de la víctima, es un hermano de crianza de la víctima ${ }^{62}$.

En este contexto, dado el deterioro de la salud de su hija debido al embarazo, AA acude a la institución prestataria de servicios de salud, denominada SALUDCOOP EPS, para que, dada la situación de violencia sexual en la que se produjo el embarazo y las malas condiciones de $\mathrm{Bв}$, se le practique un aborto que interrumpa su estado gestación.

Ante la inicial falta de pronunciamiento de SALUDCOOP EPS en cuanto a la solicitud de practicar el aborto a la joven BB, AA presenta ante instancias judiciales de primera instancia una acción de tutela con el pedido de "ordenar una inspección judicial a la víctima вв [...] para que conceptúen la invalidez y la incapacidad mental y demás circunstancias indispensables para que tome una determinación ajustada a las peticiones y a derecho" ${ }^{63}$. La empresa demandada expresa la imposibilidad de practicar el procedimiento puesto que "1. no se tiene certeza de la incapacidad de la paciente; 2 . no se aportó directamente prueba de la denuncia penal; 3 . no existe valoración sicológica que determine de manera certera la ausencia de voluntad en la paciente" ${ }^{64}$.

Más adelante, durante el trámite de la acción de tutela ante la Corte Constitucional de Colombia, al solicitarse la práctica de valoraciones médicas de Bв se manifiesta, por parte de AA, que BB ya no se encontraba en estado de

61 De acuerdo a la autora de esta metodología, se detallan seis pasos, sin embargo, se da la apertura de que, dependiendo del tema de análisis, no es obligatorio aplicarlos todos, ni en un orden concreto.

FACIO. Cuando el género suena cambios trae (una metodología para el análisis de género del fenómeno legal), cit., 65.

62 En este caso, la misma Corte Constitucional colombiana decide proteger el derecho fundamental a la intimidad de la víctima y de todas las partes involucradas, esto último por pedido expreso de la madre, para precautelar posibles afectaciones sociales posteriores; por ello, en adelante a la madre se le denomina como AA, a la víctima como вв y al presunto agresor como xx. Colombia. Corte Constitucional. Sentencia T-988 de 2007. Disponible en: http://www. corteconstitucional.gov.co/relatoria/2007/T-988-07.htm

63 Colombia. Corte Constitucional. Sentencia T-988 de 2007, cit., 8.

64 Ibíd., 10. 
gestación y tampoco había dado a luz, y que, "en vista de las circunstancias y de lo perturbadora que había resultado la situación para la joven[,] no se continuará con los trámites de tutela por cuanto estos carecían ya de objeto"65; de lo manifestado se concluye que al parecer se había inducido un aborto clandestino а вв.

- Normas relacionadas

Primeramente es necesario señalar que en Colombia el aborto se encuentra penalizado parcialmente, por cuanto se debe entender que prevalece el derecho de la mujer a interrumpir la vida cuando operen determinadas circunstancias que constituyen atenuación.

La norma penal colombiana señala que "la mujer que causare su aborto o permitiere que otro se lo cause, incurrirá en prisión de uno a tres años" ${ }^{" 66}$, pena que se atenuará y "disminuirá en las tres cuartas partes cuando el embarazo sea resultado de una conducta constitutiva de acceso carnal o acto sexual sin consentimiento, abusivo, de inseminación artificial o transferencia de óvulo fecundado no consentido" 67 .

En la sentencia en examen se articulan al análisis del caso la Convención Interamericana para la Eliminación de Todas las Formas de Discriminación contra las Personas Discapacitadas (2004), la Convención Interamericana (1978), la Constitución colombiana y otras normas uniformes sobre igualdad de oportunidades de personas con discapacidad.

Se destaca asimismo la jurisprudencia C-355 de 2006 de la Corte Constitucional de Colombia, que señala:

La exclusión constitucional de diseños legislativos que adopten posiciones absolutas obedece a que (a) cuando una constitución garantiza derechos que protegen un ámbito de decisión de la mujer en asuntos propios de su esfera vital, el legislador no puede obligar a la mujer a llevar a término su embarazo sin importar los riesgos y las cargas que ello pueda implicar; (b) el que una constitución garantice el derecho a la vida no genera como consecuencia que el aborto deba ser siempre considerado como un delito sin importar el impacto que ello tiene sobre los derechos de la mujer; (c) el que una constitución reconozca los derechos de la mujer no implica que la situación del feto sea indiferente para el derecho constitucional de tal forma que el legislador puede, y en ciertas hipótesis debe, protegerlo por medio de instrumentos que estime necesarios" ${ }^{\text {"68. }}$.

65 Ibíd., 11.

66 Colombia. Código Penal. Ley 599 de 2000. Disponible en: http://www.wipo.int/edocs/ lexdocs/laws/es/co/co028es.pdf

67 Ibíd.

68 Colombia. Corte Constitucional. Sentencia C-355 de 2006. Disponible en: https://www. corteconstitucional.gov.co/relatoria/2006/c-355-06.htm 
- Constatación de estándares y aplicación de metodología

En el caso motivo de análisis recaen en la mujer elementos que refieren una situación de doble vulnerabilidad, esto es, su discapacidad y la violencia sexual de la que fue víctima, lo cual en apariencia facilita la posibilidad de obtener autorización y prestación de servicios de salud para la práctica del procedimiento de aborto, dada la normativa en contexto.

Sin embargo, llama la atención que en primera instancia se dilata el tiempo de la solicitud, por una alegada falta de competencia en cuanto a que la causa habría debido ser "conocida por Jueces Municipales o con categoría de tales" ${ }^{69}$; más adelante, otro juzgado del mismo nivel, aunque reconoce que la entidad de salud "no había dado un trámite oportuno a la solicitud, [...] lo había dilatado de manera innecesaria" ${ }^{70}$, manifiesta la imposibilidad de concederlo, ya que "superadas las 15 semanas de embarazo las complicaciones del aborto acarrearán graves complicaciones en la vida de la madre"71.

En segunda instancia se confirma el fallo que antecede en todas sus partes, citando, "sin referencia alguna, fallos proferidos por la Corte Constitucional emitidos con antelación a la sentencia C-355 de 2006" 72 , en apoyo del señalamiento de que la práctica de aborto pondría en peligro inminente la vida de la madre, quien ya se encontraba en grave estado de salud. Ante la Corte Constitucional se realiza la revisión, que deriva en la revocatoria del pedido de apelación y en la confirmación parcial de algunos puntos de la primera instancia ${ }^{73}$.

Respecto de la aplicación del primer estándar, sobre establecer el vínculo entre violencia y discriminación, ni en primera, ni en segunda instancia existe una aplicación adecuada, ya que no se aprecia un análisis que remarque la violencia sexual de la agredida como afectación a sus derechos. Por otra parte, ya en sede de juicio por parte de la Corte Constitucional, en varias partes de la sentencia se menciona este vínculo, así como el estado de vulnerabilidad e indefensión de la víctima, además de que se aborda "la protección reforzada que se confiere a las personas discapacitadas para conceder recursos de amparo [...], realizar un análisis exhaustivo de la jurisprudencia aplicable [...] y pronunciarse ante carencia de objeto de amparo"74; sin embargo, este proceder tiene lugar cuando ya es demasiado tarde, pues el aborto clandestino ya se ha producido.

En cuanto al segundo estándar, relativo a la debida diligencia, luego del análisis se deduce que no existe cumplimiento del mismo, puesto que no se

69 Ibíd., 17.

70 Ibíd., 20.

71 Ibíd., 18.

72 Ibíd., 18.

73 Ibíd., 42.

74 Ibíd., 20-30. 
disponen medidas provisionales inmediatas para interrumpir el estado de gestación, pese a reconocerse que "la vida de la madre ya se encontraba en riesgo" "75; al contrario, la lentitud procesal conlleva el desarrollo natural del embarazo.

En cuanto al tercer estándar, tampoco existe indicio de la realización de un análisis exhaustivo sobre las posibles normas aplicables; así por ejemplo, en apelación "se hizo caso omiso de la jurisprudencia nacional colombiana C-355-06" "76, y tampoco se hace referencia a instrumentos supranacionales como la Resolución 2003/45 del Comité de Derechos Humanos o a la Recomendación 19 de la CEDAW.

En este contexto se procede con la aplicación del paso 1 de la metodología para el análisis de género, es decir, "comprender la generalización de la discriminación y subordinación de la mujer [...] que nos hace sospechar de la presunta neutralidad de las estructuras" $" 77$, por lo cual es claro reconocer que el caso en contexto muestra cómo "en nuestras sociedades se ha enfrentado el problema del aborto desde la perspectiva del hombre [...] cuya protección básica es la vida intrauterina"78; es así como aun tratándose de una mujer que cuenta con protección reforzada, el desenvolvimiento judicial enfatiza en que no se tiene certeza de la incapacidad de la paciente ${ }^{79}$.

El paso 2 de la metodología requiere profundizar en el sexismo que se manifiesta de diversas formas; en este caso opera una insensibilidad al género, por cuanto se ignora la variable sexo como socialmente importante o válida; y un doble parámetro, puesto que una misma conducta se valora de distintas maneras para cada $\operatorname{sexo}^{80}$. En cuanto a la primera forma de sexismo, no se dan respuestas claras a la necesidad de la mujer, por el contrario, se cuestiona la voluntad de вв, sobre si consintió o no el acto sexual, y si el aborto es su voluntad o la de su madre; también opera el doble parámetro, pues se asigna a la mujer un rol de madre, que se antepone a su situación de vulnerabilidad, indistintamente de las circunstancias de violencia sexual en que se produjo el embarazo ${ }^{81}$, rol que, como es apenas obvio, sería imposible de anteponer respecto de un varón.

De acuerdo al paso 3 de la metodología, se debe identificar la mujer establecida como el otro, por lo que cabe plantearse cómo afecta esta resolución

75 Colombia. Corte Constitucional. Sentencia C-355 de 2006, cit., 20.

76 Ibíd., 20.

77 FACIO. Cuando el género suena cambios trae (una metodología para el análisis de género del fenómeno legal), cit., 63-64, 75-76.

78 FACIO, A. Metodología de Género para el Análisis del Fenómeno Legal. En ÁviLA, R.; Salgado, J. y Valladares, L. (comps.), El género en el derecho. Ensayos críticos. Quito: Ministerio de Justicia y Derechos Humanos, 2009, 189.

79 Colombia. Corte Constitucional. Sentencia T-988 de 2007, cit., 17.

80 FACIO. Cuando el género suena cambios trae (una metodología para el análisis de género del fenómeno legal), cit., 63-64, 88-89.

81 Colombia. Corte Constitucional. Sentencia T-988 de 2007, cit., 36-37. 
a la mujer en mención ${ }^{82}$, haciendo posible inferir que en este caso prevalece como el otro la mujer- madre, y que se la invisibiliza por el hecho de serlo, pese a existir una situación de discapacidad. Lo anterior en tanto prevalece el valor de la vida en abstracto, lo que conlleva la realización "de abortos clandestinos y la consecuente desprotección de esa vida intrauterina que tanto se desea proteger" 83 , sin dejar de lado la total restricción del derecho de вв.

El paso 4 requiere realizar el análisis del caso con relación a los otros dos componentes del sistema jurídico -sustantivo y político-cultural-, y cabe cuestionarse sobre "qué procedimientos existen para la interpretación de la ley" 84 , en respuesta a lo cual es posible referir que el procedimiento en las instancias primera y segunda siempre atendió a dilatar el accionar favoreciendo la vida intrauterina. A partir de ello se define una clara influencia desde el plano estructural judicial, que invisibiliza la situación de la mujer y desatiende sus necesidades; pese a existir normas y jurisprudencia aplicable -plano sustantivo-, no se emplean o se evitan, lo cual conduce a que AA acuda a soluciones directas, clandestinas y peligrosas, dado que la manera en que "la ley es interpretada, será lo que la mayoría de la gente considere que es el verdadero contenido" 85 .

\section{B. Expediente 002790-2009, Perú}

\section{- Antecedentes}

Se analiza el proceso bajo el pedido de recurso de nulidad por parte de B.Y.A.H., por alegarse que se debe resolver la situación jurídica del acusado F.G., mediante juicio oral, en lo que concierne al cometimiento de los delitos de homicidio calificado e instigación al suicidio, a fin de determinar su responsabilidad. En este caso, la mujer denominada N.I.H.A., según los relatos de los hechos, fue víctima de abusos físicos constantes por parte de su cónyuge, producto de los cuales la agraviada sufrió un aborto, lo que podría haberla inducido al suicidio mediante ingesta de veneno; así también, la Fiscalía plantea la tesis de que su pareja la envenenó ${ }^{86}$.

Según lo manifestado por un vecino, el 15 de julio del año 2007, mientras dialogaba con el acusado, "escuchó unos quejidos provenientes de la habitación de la agraviada, lo cual comunicó al imputado, quien al ingresar,

82 FACiO. Cuando el género suena cambios trae (una metodología para el análisis de género del fenómeno legal), cit., 63-64, 88-89, 95.

83 FACio. Metodología de Género para el Análisis del Fenómeno Legal, cit., 190.

84 FACIO. Cuando el género suena cambios trae (una metodología para el análisis de género del fenómeno legal), cit., 63-64, 101. 199.

85 Facio. Metodología de Género para el Análisis del Fenómeno Legal, cit., 181-224,

86 Perú. Sala Penal Permanente de Huancavelica. Sentencia 2790-2009, 4. Disponible en: https://2019.vlex.com/\#vid/472868106 
manifestó que había tomado veneno [...] y vio que botaba espuma por la boca" ${ }^{87}$. El fiscal superior de la Segunda Fiscalía Mixta de Huancavelica emitió un dictamen por el que solicitó el archivo de la causa, referente a los delitos de homicidio calificado y de instigación al suicidio, por no configurarse el delito ${ }^{88}$; por su parte, el Supremo Tribunal manifestó que "le está vedado al órgano jurisdiccional ordenar al Fiscal que acuse y, menos, asumir un rol activo en la acusación" 89 .

- Normas relacionadas

Primeramente, se debe indicar que en el Estado peruano el aborto está considerado como un delito, tal como lo establecen los artículos 114 y siguientes de la norma penal, que tipifica el "autoaborto, aborto consentido, sin consentimiento, preterintencional, terapéutico, sentimental y eugenésico" ${ }^{90}$, siendo inimputable solamente el aborto terapéutico.

Otras de las normas penales que se relacionan en este caso son el artículo 108, que tipifica "el homicidio calificado, cuya pena privativa de libertad es no menor de veinticinco años", y el numeral 2 del mismo artículo, que establece la circunstancia de "facilitar o a su vez, ocultar otro delito" este caso el de aborto.

Se destaca la jurisprudencia ejecutoria vinculante 1678-2006, del 13 de abril de $2007^{[92]}$, por señalarse en ella que "al mantenerse activo un proceso por delito de parricidio, en contra del acusado, y concurrir dos pronunciamientos previos de Fiscalía de no acusar, no existiría posibilidad de que se resuelva la imputación"93.

\section{- Constatación de estándares y aplicación de metodología}

En el presente caso concurren varias situaciones que requieren alcanzar el sentido de justicia de género, ya que la mujer es víctima de maltrato físico por parte de su pareja, lo cual provoca en ella un aborto y más adelante la instiga a cometer suicidio. Por su parte, el dictamen fiscal señala que no se configura el delito de homicidio culposo y que "se considera que el parricidio excluye dicho delito, ya que en el presente caso uno de los cargos en contra

87 Ibíd., 2.

88 Ibíd., 3.

89 Ibíd.

90 Perú. Código Penal, Decreto Legislativo 635. Disponible en: https://apps.contraloria. gob.pe/unetealcontrol/pdf/07_635.pdf

91 Ibíd., art. 119.

92 Según tal jurisprudencia, si el fiscal no formula acusación, más allá de la posibilidad de incoar el control jerárquico, está vedado al órgano jurisdiccional ordenar al fiscal que acuse, y menos asumir un rol activo y, de oficio, definir los ámbitos sobre los que discurrirá la selección de los hechos, que solo compete a la Fiscalía

93 Perú. Sala Penal Permanente de Lima. Queja 1678-2006, 6. Disponible en: https:// www.mpfn.gob.pe/escuela/contenido/actividades/docs/4055_rqueja_001678_2006_princ.acusat. sobreseim.spp_csmc_13.4.07.pdf 
del imputado es el de envenenar a su cónyuge y dejarla morir"94 ${ }^{\text {, solicitando }}$ así el archivo de la causa.

Dado el pronunciamiento del dictamen de sobreseimiento del acusado -en cuanto a los delitos de homicidio culposo e instigación al suicidio-, se solicita su nulidad, por motivo de que en los delitos antes indicados la posible sanción de privación de libertad sea de mayor tiempo ${ }^{95}$; por ello, la Sala confirma el criterio de Fiscalía y "declara no haber mérito para pasar a juicio oral" "96 , señalando además que "en los delitos de instigación al suicidio y homicidio calificado, imputados al encausado F.G., no concurren los presupuestos legales para su configuración, más aún si se le viene procesando por delito de parricidio" 97.

Al realizarse la constatación de cumplimiento de estándares sobre articular la violencia física como vulneración a los derechos humanos de la mujer, en el desenvolvimiento del caso, pese a señalarse múltiples testimonio de los vecinos del lugar, no se identifica un énfasis en la situación de extrema violencia a la que era sometida la occisa; más bien, se manifiesta que "no se configura el homicidio, por envenenamiento que sea capaz de poner en riesgo la vida, tampoco la instigación al suicidio [...] por lo que no existe mérito para pasar a juicio oral"98.

De acuerdo al segundo estándar, sobre debida diligencia, en el caso la mujer es víctima de violencia física que le produce un aborto y procede a cometer suicidio, lo cual no es considerado por el pronunciamiento fiscal puesto que se solicita archivo y se procede por parricidio, que excluye las demás investigaciones ${ }^{99}$; con lo cual no se constata un proceder que enfatice en la perspectiva de la mujer para el alcance de la justicia, cuando incluso la casuística del Sistema Interamericano ha señalado que "si los actos violatorios de derechos, provenían de particulares, el Estado tenía el deber de diligencia reforzado $[\ldots]$ ya que el no hacerlo podría generarle responsabilidad internacional" 100 .

En cuanto al tercer estándar, sobre un escrutinio de leyes exhaustivo, tampoco se identifica su aplicación, ya que la Sala centra sus análisis en su propia jurisprudencia para indicar que, "como este Tribunal en reiterada jurisprudencia viene sosteniendo[,] si el representante del Ministerio Público

94 Perú. Código Penal, cit., art. 108. Disponible en: https://apps.contraloria.gob.pe/unetealcontrol/pdf/07_635.pdf

95 En la norma penal peruana, el homicidio calificado cuenta con una pena no menor de 25 años; la instigación al suicidio, con una de entre 1 y 4 años, y el parricidio, con una pena no menor de 15 años. Cfr. Perú. Código Penal, art. 107.

96 Perú. Sala Penal Permanente de Lima. Queja 1678-2006, cit., 2.

97 Ibid., 3.

98 Ibid., 3-4.

99 Ibid., 2-4.

100 Corte IDH. Caso López Soto y otros vs. Venezuela, cit. 
no refiere acusación, y el superior [...] señala conformidad, le está vedado al órgano jurisdiccional que acuse" ${ }^{101}$. Ante ello, se apunta que bien podría haberse acudido a normas del Sistema Interamericano para mejorar su decisión con el objeto de "actuar con la debida diligencia para prevenir y sancionar la violencia contra la mujer" 102 .

De acuerdo al paso 1 de la metodología para el análisis de género, se toma conciencia de un claro estado de subordinación de la mujer en el caso, al señalarse que el cónyuge "le amarraba la boca y le propinaba patadas en el cuerpo, con lo cual le habría producido un aborto, y le manifestaba que no era nada y que recién iba a estar tranquilo con su muerte" 103 .

El paso 2 de la metodología se refiere a identificar la forma de sexismo presente en el caso; de acuerdo a lo analizado, dado que las decisiones judiciales se limitan a las normas penales, sin tomar en cuenta a la mujer desde el punto de vista de la desigualdad y la violencia física de la cual fue víctima, opera una insensibilidad con respecto al género, pues no se toma en cuenta el hecho de que "no se consideró las desigualdades entre los sexos, es decir, la variable género como relevante" 104 .

Respecto del paso 3 de la metodología, este conlleva identificar a la mujer como el otro; en este caso, la mujer que sirve de sustento, modelo o estereotipo en el caso analizado es la mujer como pareja, que debe cumplir un rol de fragilidad y sumisión ${ }^{105}$ aunque ello le cueste la vida. Lo anterior ciertamente la perjudica, ya que desde esta perspectiva existe una clara invisibilización de las agresiones, el aborto causado y la instigación al suicidio, que permitirían ampliar la visión del dictamen fiscal.

En cuanto al paso 4 de la metodología, en el caso analizado se percibe la existencia de estructuras judiciales machistas en los pronunciamientos del Ministerio Público, al dejar de lado factores que denotaban que la persona procesada mantenía una relación caracterizada por las agresiones y la violencia, lo que finalmente pudo haber motivado el suicido de la mujer. Esto influye en los otros componentes, político-cultural y sustantivo, puesto que "el acceso que tenga la gente a la administración de justicia influye en la doctrina jurídica que se va creando" 106 y enfatiza en la perpetuación de estructuras de desigualdad.

101 Perú. Sala Penal Permanente de Lima. Queja 1678-2006, cit., 3.

102 OEA. Convención Interamericana para Prevenir, Sancionar y Erradicar la Violencia contra la Mujer, cit., arts. 1, 2, 3 y 7.

103 Perú. Sala Penal Permanente de Lima. Queja 1678-2006, cit., 1-2.

104 FACio. Cuando el género suena cambios trae (una metodología para el análisis de género del fenómeno legal), cit., 88.

105 Ibíd., 96.

106 FACio. Metodología de Género para el Análisis del Fenómeno Legal, cit., 181-224, 199. 
C. Mujer indígena encarcelada por inducirse un aborto, Bolivia

- Antecedentes

Se analiza el caso de Helena ${ }^{107}$ una mujer indígena boliviana que es detenida inmediatamente después de haber sido atendida en el Hospital de Maternidad Percy Boland en Santacruz por complicaciones de salud surgidas luego de ingerir pastillas para inducirse un aborto. En este caso la mujer habría sido víctima de una violación, la cual no fue denunciada por ella por temor a no ser creída; por otra parte, existió desconocimiento de que podía acceder a un aborto legal y de los riesgos legales que esto conllevaría.

La mujer tomó una pastilla conocida como misoprostol durante su vigésima tercera semana de gestación; una vez ingresada en el centro de salud por las graves complicaciones sufridas, fue esposada y detenida durante los diez días que duró su hospitalización. Luego de este tiempo fue denunciada ante la Fiscalía por el Defensor de los Niños y Adolescentes, por el cometimiento del crimen de aborto; la etapa de investigación del caso incluyó redadas y cierre de las farmacias por la venta del medicamento sin la presentación de la correspondiente receta médica.

El 3 de febrero de 2012, con una acusación oficial, Helena fue puesta bajo detención preventiva, en la cárcel de Palmasola, en Santa Cruz (Bolivia). El encarcelamiento tuvo lugar sin que mediara sentencia, y la mujer fue colocada con otras internas ya sentenciadas por otros crímenes. La mujer fue luego sentenciada a dos años de prisión por haber cometido el delito de aborto, lo que la mantuvo privada de su libertad durante ocho meses. Posteriormente, Helena se acogió a lo establecido en la legislación boliviana, que permite el cumplimiento de la sentencia fuera de la prisión siempre y cuando se pida y reciba un perdón judicial por haber cometido el crimen.

- Normas relacionadas

En el caso se articula la norma constitucional boliviana, que "reconoce los derechos en equivalencia de condiciones para hombres y mujeres" ${ }^{108}$. De manera específica, la mencionada norma estipula que "todas las personas, en particular las mujeres, tienen derecho a no sufrir violencia física, sexual o psicológica, tanto en la familia como en la sociedad" ${ }^{109}$, y garantiza tanto

107 En este caso no se analiza una sentencia directa, puesto que en el Estado boliviano "todos los documentos oficiales relacionados con procesar casos de aborto se guardan en reserva, en la base de datos de la Fiscalía"; así pues, se utiliza para la víctima el nombre ficticio de Helena, el mismo que es empleado en la fuente de información consultada.

Kane, G.; Galli, B. y Skuster, P. Cuando el aborto es un crimen: la amenaza para mujeres vulnerables en América Latina. 4. ${ }^{\text {a }}$ ed. Carolina del Norte: Ipas, 2013, 5.

108 Bolivia. Constitución Política de 2009, art. 11, lit. 1. Disponible en: http://www.wipo. int/edocs/lexdocs/laws/es/bo/bo033es.pdf

109 Ibid., art. 15, lit. 2. 
a la mujer como al hombre "el ejercicio de sus derechos sexuales y sus derechos reproductivos" 110 .

De manera concreta, es importante señalar que el aborto en Bolivia se ha considerado como un delito tipificado en el Código Penal, según lo cual existen las siguientes figuras relacionadas con esta práctica: "aborto con lesión o muerte, honoris causa, impune, preterintencional, culposo y como práctica habitual" 111 , siendo la sanción prevista para estos delitos de entre seis meses y seis años de prisión o reclusión. Se establece además la figura de aborto impune, en virtud de la cual el delito no será punible, salvo en casos de violación una vez iniciada la acción penal ${ }^{112}$.

En el caso en examen cobra relevancia la jurisprudencia del Tribunal Constitucional Plurinacional 0206/2014, según la cual, entre otros puntos, "se elimina la orden judicial como requisito, para obtener aprobación de realizar un aborto legal" ${ }^{113}$, en casos de haberse sufrido una violación sexual.

- Constatación de estándares y aplicación de metodología

En el caso en mención se identifica una aplicación literal de la norma penal vigente en el año 2012, fecha en la que el caso acontece, respecto del requisito de presentación de documentos sobre el inicio de la acción penal por violación, para que el aborto sea permitido. Este proceder de estricto cumplimiento del derecho punitivo favorece el formalismo, por lo que se sentencia a la mujer con pena privativa de la libertad.

De acuerdo al primer estándar, relativo al deber de articular la violencia y discriminación como vulneración de los derechos humanos, no se constata su aplicación puesto que, como se señalara, existe un criterio absoluto para aplicar el derecho positivo existente, sin tomar en cuenta la rusticidad de la mujer, ni el contexto de violencia sexual que produjo el embarazo ${ }^{114}$.

En cuanto al segundo estándar, sobre debida diligencia, tampoco se evidencia un proceder que favorezca la situación de la mujer; por el contrario, dadas las circunstancias, esta actuación sería exigible no solo del aparato judicial, sino del mismo Estado, ya que "intervienen en la afectación de derechos tanto actores estatales, como no estatales" 115.

Respecto del tercer estándar, referido a aplicar un estricto escrutinio de todas las leyes aplicables, en el caso se hace visible que tampoco se aplica;

110 Ibid., art. 66.

111 Bolivia.Ley del Código Penal, art. 263 ss. Disponible en: https://www.oas.org/juridico/ spanish/gapeca_sp_docs_bol1.pdf /

112 Ibid., art. 266.

113 Ibid., arts. 258 y 266.

114 Kane, Galli y SKuster. Cuando el aborto es un crimen: la amenaza para mujeres vulnerables en América Latina, cit., 6.

115 Red de Defensorías de Mujeres de la Federación Iberoamericana del Ombudsman. Debida diligencia en el acceso a la justicia y tutela judicial efectiva de las mujeres víctimas de violencia familiar: alcances, limitaciones y propuestas, cit., 26. 
de ahí que la sujeción de este país a los instrumentos internacionales sobre derechos de las mujeres establezca un compromiso tácito, de acoger y utilizar preceptos, como la Convención de Belem do Pará (1994) o la Resolución 2003/45 de la Comisión de Derechos Humanos, que quizá hubieran podido comportar un accionar diferente.

En cuanto al paso 1 de la metodología para el análisis de género, corresponde tomar conciencia plena del estado de subordinación de la mujer, por lo que es posible señalar que existe pleno conocimiento de que en el caso se verifica una amplia situación de desigualdad estructural, dada la condición étnica de Helena, una indígena guaraní que vive en extrema pobreza con su pequeña hija en la ciudad de Santa Cruz y que quedó embarazada a causa de una violación ${ }^{116}$. Las estadísticas a nivel mundial refieren que "las mujeres en Latinoamérica son víctimas de un alto grado de violencia sexual; lo cual se agudiza en aquellas que pertenecen a diversa condición étnica" ${ }^{117}$; a lo que se suma la falta de denuncia por temor, vergüenza, posibles represalias, revictimización, desconocimiento de la ley y falta de recursos económicos.

Respecto del paso 2 de la metodología, sobre identificar las formas de sexismo, en el caso es posible hacer referencia a la existencia de sobreespecificidad, "que consiste en presentar como específico de un sexo, ciertas actitudes" $" 118$, ya que en el caso todos los procedimientos se desarrollan con base en que lo específico del sexo femenino es la maternidad. Por lo tanto, en este caso el derecho a la vida del nasciturus rebasa el trasfondo del derecho de la mujer a tomar decisiones sobre su propio cuerpo; incluso, teniendo en cuenta que la misma norma constitucional boliviana estipula "iguales derechos sexuales y reproductivos, tanto para el hombre, como para la mujer" 119 .

Siguiendo el paso 3 de la metodología, en cuanto a identificar a la mujer como el otro, en el caso analizado la mujer es considerada en su rol de reproductora, contemplando así "protecciones o leyes para la maternidad [...] mas no para las necesidades de la mujer como persona" ${ }^{120}$; claramente, del accionar se deduce la imposición de castigo ante la negación de Helena a cumplir este rol.

El paso 4 de la metodología conlleva el análisis de la influencia entre los tres componentes del sistema jurídico, a partir de lo cual se precisa que la

116 Kane, Galli y Skuster. Cuando el aborto es un crimen: la amenaza para mujeres vulnerables en América Latina, cit., 6.

117 Bott, S.; Guedes, A. y AdAms, J. Violencia contra las mujeres en América Latina y el Caribe. Análisis comparativo de datos poblacionales de 12 países. Washington, D.C.: Organización Panamericana de la Salud, 2014, 40.

118 FACio. Cuando el género suena cambios trae (una metodología para el análisis de género del fenómeno legal), cit., 85.

119 Bolivia. Constitución Política de 1999, cit., art. 66.

120 FACio. Cuando el género suena cambios trae (una metodología para el análisis de género del fenómeno legal), cit., 96. 
presencia de sexismo en el plano estructural boliviano, en casos de aborto inducido, cuando ha existido violación, influye claramente en los componentes sustantivo y político-cultural, puesto que "si el problema del aborto se analizara desde una perspectiva de género, se tendría que analizar no solo el valor vida en estricto, sino al mismo tiempo tantos otros factores más" ${ }^{121}$, que quizá conducirían a modificaciones de la perspectiva legal en el plano sustantivo y político-cultural. Cabe subrayar que en este país se ha emitido la jurisprudencia 206-2014, por la cual se eliminó el requisito de presentación de denuncia para obtener el permiso de aborto legal, si bien para el caso en estudio aún no estaba vigente.

\section{Sentencia 082-16-SEP-CC. Corte Constitucional de Ecuador}

\section{- Antecedentes}

El caso se relaciona con la presentación del recurso de acción extraordinaria de protección, por parte de Segundo Rubén Torres Vásquez en representación de su hija, Lucía Elizabeth Torres Dávila, en contra del director de la Escuela Superior Militar de Aviación Cosme Rennella, entidad que es parte de la Fuerza Aérea Ecuatoriana, con la finalidad de impugnar una sentencia de apelación que declaró improcedente una acción de protección interpuesta ante instancia inferior.

El contexto que motivó la presentación inicial del caso ante instancia judicial de primer nivel refiere que, con fundamento en las normas constitucionales sobre no discriminación en contra de la mujer embarazada, se deje sin efecto "el documento de baja voluntaria simulada suscrito por la ex cadete y que se ordene la inmediata reintegración de su hija al rango de cadete de la Fuerza Aérea Ecuatoriana" 122.

Entre los antecedentes se toman en consideración: el certificado emitido por el jefe del Departamento de Ginecología de la Clínica de la Fuerza Aérea, quien señala que "atendió a Lucía Torres Dávila el 3 de abril de 2010, presentando un embarazo de seis semanas”. También se toma en cuenta el certificado de un médico privado, emitido con pocos días de diferencia del anterior, en donde se señala que la atención responde a un "aborto incompleto, correspondiente a cinco o seis semanas de gestación" ${ }^{23}$, con base en lo cual se declaró improcedente el recurso.

En instancia de apelación de sentencia existe una ratificación por parte de la Sala Única de la Corte Provincial de Justicia de Santa Elena, que se sustenta principalmente en que la "ex cadete solicitó sin presión de ninguna

121 FACiO. Metodología de Género para el Análisis del Fenómeno Legal, cit., 190.

122 Ecuador. Corte Constitucional. Sentencia 082-16-SEP-CC, 4. Disponible en: http://portal. corteconstitucional.gob.ec:8494/FichaRelatoria.aspx?numdocumento=082-16-SEP-CC

123 Ibíd. 
clase la baja voluntaria de la institución" ${ }^{24}$, y además se señala que "en la versión rendida por la afectada ante el juez a quo, nunca se señaló persona alguna que haya obligado a la ex cadete a solicitar la baja por su estado de gestación"125.

- Normas relacionadas

El Estado ecuatoriano ha suscrito los principales instrumentos específicos sobre derechos de las mujeres, por ejemplo, las convenciones para la Eliminación de Todas las Formas de Discriminación contra la Mujer (1979) y de Belem do Pará (1994), de lo cual se deriva que el país adopta una postura abierta en cuanto a derechos como "igualdad y prohibición de toda forma de discriminación" 126 , prohibición de despido o "discriminación en contra de las mujeres en estado de gestación y la garantía de los derechos reproductivos en el caso de personas trabajadoras" 127.

Así mismo, se relacionan los artículos 43 numeral 1 y 45 de la Constitución en donde se señala que "el Estado garantizará a las mujeres embarazadas y en periodo de lactancia los derechos a no ser discriminadas por su embarazo en los ámbitos educativo, social y laboral", y que "el Estado reconocerá y garantizará la vida, incluido el cuidado y protección desde la concepción".

En el caso analizado se ha presentado en primera instancia una acción de protección, por lo tanto, como norma relacionada se encuentra el artículo 88 de la Constitución, cuyas finalidades relacionadas con el caso son "la protección directa de derechos constitucionales por acción u omisión de autoridad pública [...] si la persona afectada se encuentra en estado de subordinación, indefensión o discriminación".

- Constatación de estándares y aplicación de metodología

En la sentencia motivo de análisis llama la atención el modo de proceder del Juzgado Décimo Sexto de lo Civil y de la Sala Única de la Corte Provincial de Justicia, en la primera y la segunda instancia, por centrarse únicamente en una solicitud escrita de baja voluntaria presentada por Lucía Elizabeth Torres Dávila, lo cual se deduce del siguiente extracto de la sentencia impugnada:

... no existe un acto, una resolución que haya violado los derechos fundamentales de la señorita Lucía Elizabeth Torres Dávila, en virtud de que la referida ciudadana mayor de edad y como tal conocedora de sus derechos y obligaciones, por su propia decisión presentó mediante oficio s/n. el 08 de abril del 2010, una solicitud de baja voluntaria ${ }^{128}$.

124 Ibíd., 2.

125 Ibíd., 5.

126 Ecuador. Constitución de la República de Ecuador, arts. 66 y 331, inc. 2. Disponible en: https://www.oas.org/juridico/pdfs/mesicic4_ecu_const.pdf

127 Ibid., art. 332, inc. 2.

128 Ecuador. Corte Constitucional. Sentencia 082-16-SEP-CC, cit., 2. 
Resulta incomprensible que no se tomen en cuenta las circunstancias bajo las cuales se presentó dicha solicitud, que bien pudieron deducirse de los relatos aportados al caso. Así, en ellos se hace alusión a que la mujer supo de su embarazo el 6 de abril y apenas dos días después presentó su pedido de baja, la cual fue aceptada y tramitada de manera inmediata con fecha 8 de abril; y más adelante se señala que "luego a los pocos días según certificado privado [...] presentaba enfermedad pélvica, inflamatoria por aborto incompleto" 129 .

Esto contradice lo manifestado en la sentencia respecto de que el pedido de baja voluntaria "debe haber sido con el ánimo de proteger a su hijo que estaba con vida en el vientre materno" 130 , y refuerza el supuesto de que la mujer pudo haber tenido presiones directas para presentar la solicitud, lo cual pudo afectarla hasta el punto de provocarle un aborto, o bien conducirla a tomar la decisión de abortar.

Ante tales circunstancias, la parte accionada orienta la atención a que estaba obligada a aceptar el pedido para no transgredir derechos constitucionales sobre la protección de la vida del nasciturus, cuando en realidad la entidad militar incurre en un acto de omisión por haber aceptado inmediatamente la solicitud y no haber considerado, en su lugar, la concesión de un permiso temporal por maternidad para no separar a la mujer de la institución debido a su embarazo.

En adelante, el desenvolvimiento del proceso se centra en la inexistencia de vulneración de derechos constitucionales de la mujer, conduciendo a la negación de recursos, incluso en sede de Corte Constitucional, la cual manifiesta que "los jueces sustentan la conclusión final del fallo, esto es la ausencia de derechos constitucionales vulnerados, a través de un análisis argumentativo y jurídico suficiente, claro y pertinente [...] conforme a la naturaleza, objeto y razón de ser de la acción de protección de carácter constitucional[;] de este modo se verifica la acción diligente de los operadores" ${ }^{131}$.

Bajo estas circunstancias, no se constata el cumplimiento del primer estándar, en cuanto al vínculo entre discriminación, violencia y restricción de derechos humanos, ya que, pese a que el actor ha tratado de solicitar el amparo de los derechos a la no discriminación de la mujer por su estado de embarazo, toda la atención se ha centrado en la voluntariedad de ella por el hecho de haber presentado un oficio de baja.

En cuanto al estándar sobre debida diligencia, no se constata un proceder judicial rápido, que conduzca a la reparación del derecho vulnerado, pues el trámite judicial ha proseguido sin que se disponga al menos la reincorporación de la mujer al ente militar. Por el contrario, se señala que "ha existido

129 Ibid., 2.

130 Ibid.

131 Ibid., 3. 
una debida diligencia de los jueces provinciales y la ejecución de la misma se ha cumplido al negarse la apelación propuesta" 132 .

De acuerdo al tercer estándar, sobre aplicar un estricto escrutinio, no se evidencia que los jueces lo observen, puesto que no se han citado instrumentos internacionales específicos sobre violencia o discriminación como la Convención de Belem do Pará (1994) o la Recomendación General 19 de la CEDAW, y la motivación se basa únicamente en normas de carácter nacional, en donde se señala que "la motivación no solo implica [...] citar normas aplicables al caso concreto, sino que además deben ser el resultado de la lógica y la argumentación jurídica"133.

De acuerdo al paso 1 de la metodología para el análisis de género del fenómeno legal, respecto de la toma de conciencia de la subordinación de la mujer, con base en las circunstancias señaladas en el caso se tiene claridad sobre la relación desigual existente en el interior de la entidad militar, puesto que esta última logra ejercer tal presión que conduce a la mujer a presentar una baja voluntaria no obstante saber que cuenta con la posibilidad del permiso de maternidad.

De acuerdo al paso 2 de la metodología, respecto de identificar la forma de sexismo presente en el caso, luego del análisis se ha podido identificar la sobreespecificidad, enfatizando en que la solicitud de baja se tramitó ágilmente para "precautelar la vida de la ex cadete y del nasciturus, toda vez que debido a los ejercicios físicos que se realizan durante el períodos de formación [...] corría riesgo su estado de gestación" ${ }^{134}$. Tal razonamiento permite verificar la poca o nula valoración del derecho de Lucía Elizabeth Torres Dávila a permanecer en la institución militar y no ser discriminada por su estado de embarazo, y se deduce la acción por omisión de la institución, al no haber extendido algún tipo de permiso por maternidad.

Según el paso 3 de la metodología, en cuanto a señalar que la mujer se identifica como el otro, en el caso se presentan dos facetas: la de la mujer como madre y la de la mujer que en sentido discriminatorio debe dedicarse a ciertas áreas profesionales en las que es más usual su desenvolvimiento; de ahí que se manifieste que "la estudiante corría riesgo por su estado de gestación [...]; por lo que, el director indica que no se podía obligar a la estudiante a continuar en la institución"135.

En cuanto al paso 4 de la metodología, referido a analizar la influencia del componente estructural hacia los otros dos componentes del sistema jurídico, de lo analizado se sostiene que, al existir discriminación judicial en cuanto al componente estructural, que revierte la controversia hacia la mujer por

132 Ibid., 13.

133 Ibid., 15.

134 Ibid., 6.

135 Ibid. 
presentar su pedido voluntario de baja, se influye de manera determinante en el componente formal-normativo, lo cual desvirtúa el análisis y define la inexistencia de vulneración. En consecuencia, se siguen validando comportamientos discriminatorios y estereotipos en el componente político-cultural, lo que perpetúa las estructuras de desigualdad que perjudican a la mujer al restringir sus derechos.

\section{CONCLUSIÓN}

El derecho fundamental de la mujer a tomar decisiones sobre su propio cuerpo en contextos de violencia sexual se torna complejo, principalmente, en ámbitos cuya realidad normativa expresa una larga trayectoria conservadora, en donde el aborto, de manera general, es una práctica ilegal, que toma matices de no penalización en ciertos casos. Sin embargo, pese a existir tal disposición normativa, su aplicabilidad en el marco judicial se apega a ciertas condiciones, que muchas de las veces terminan por desvirtuar la esencia del derecho, restringiendo a la mujer el ejercicio de dicha potestad.

Así por ejemplo, en Ecuador las circunstancias por las cuales el aborto no es punible se limitan a dos: cuando "se ha practicado para evitar un peligro para la vida o salud de la mujer embarazada" y cuando el embarazo es producto "de una violación en una mujer que padezca de discapacidad mental" 136 . No obstante, en las dos circunstancias permitidas la carga de la prueba recae de manera directa en la mujer, puesto que debe comprobarse a cabalidad que no existía otro medio para evitar el peligro de la vida de la madre y que la violación no se produjo debido a una relación sexual consensuada; de tal manera, este derecho fundamental adolece de barreras que ciertamente impiden el alcance de la justicia de género.

En este contexto, las mujeres que toman esta decisión deben recurrir a la clandestinidad, lo que no solo pone en riesgo su vida sino que transgrede este derecho individual. En el estudio de Ortiz-Prado y otros se manifiesta que "aproximadamente 48.000 mujeres mueren cada año, debido a complicaciones de abortos inseguros, $86 \%$ de los cuales ocurren en países en desarrollo"; de tal manera, "los abortos inseguros y clandestinos representan un gran riesgo para las mujeres y [...] un problema urgente de salud pública" 137.

Otra problemática que agrava la situación es la inexistencia de estadísticas oficiales relacionadas con la muerte por causa de abortos; y tampoco existe

136 Ecuador. Código Orgánico Integral Penal de 2014, art. 150, nums. 1 y 2. Disponible en: https://tbinternet.ohchr.org/Treaties/CEDAw/Shared\%20Documents/ECU/INT_CEDAW_ARL_ ECU_18950_S.pdf

137 Ortiz-Prado, E.; Simbaña, K.; Gómez, L.; Stewart-Ibarra, A.; Scott, L. y CevallosSIERRA, G. Abortion, an increasing publichealth concern in Ecuador, a 10-year population-based analysis. En Pragmatic and Observational Research. Dovepress. 2017, 8, 129-135. Disponible en: https://www.ncbi.nlm.nih.gov/pmc/articles/PMc5516879/pdf/por-8-129.pdf 
información segmentada o específica que permita realizar una aproximación directa a esta realidad social, pues los datos sobre el tema provienen en gran parte de investigaciones académicas, estudios realizados por organismos internacionales, informes de organismos no gubernamentales y colectivos feministas, lo cual dificulta el "distinguir entre abortos arbitrarios, abortos auto inducidos y abortos involuntarios" 138 ; como resultado de ello, las mujeres siguen siendo sancionadas por ejercer su propio derecho.

En esta misma línea, existen resistencias culturales, religiosas, sociales e incluso políticas, que influyen de manera decisiva en la evolución normativa y su aplicabilidad, lo que conlleva la perpetuación de estructuras esencialistas, que terminan por rebasar la posibilidad de una verdadera consolidación del sistema jurídico, que comulgue con la naturaleza progresiva del derecho.

A partir del análisis comparado de casos se deduce que, pese a la disposición normativa constitucionalista, de clara apertura a los derechos humanos, la falta de sensibilidad y perspectiva de género en el desenvolvimiento judicial es una problemática que podría estarse presentando de manera generalizada, ya que en muchos casos los tribunales resuelven sin tomar en consideración los estándares internacionales y bajo un criterio sesgado, que depende del tipo de derecho sometido a su conocimiento para asumir una postura sobre la resolución.

De este modo, al tratarse de una potestad jurídica sumamente paradigmática, y contando los países comparados con normativa parcializada -en donde el proceder era legal-, la entidad de salud competente se resiste al procedimiento, y el desenvolvimiento judicial se inclina por examinar de manera minuciosa la responsabilidad femenina ante el cometimiento del delito de aborto, en lugar de adelantar el análisis desde la perspectiva del derecho de la mujer a decidir y a no ser sometida a violencia. En los casos analizados se emitieron resoluciones tardías y perjudiciales, que derivaron en desistimiento de la acción por inexistencia de embarazo, archivo de proceso sobre aborto e instigación al suicido por parte de la pareja, prisión con pedido de perdón por el crimen de aborto cometido, e instigación al aborto con baja voluntaria deshonrosa de las fuerzas armadas.

Finalmente, se torna necesaria una ruptura de patrones culturales y sociales, que supere injerencias en los tres componentes del sistema jurídico, sustantivo, estructural, y político-cultural, y que conlleve cambios para materializar el derecho de la mujer a tomar decisiones sobre su propio cuerpo en el marco de una vida libre de violencia, de cara al Sistema Internacional de los Derechos Humanos, en atención a la perspectiva del sujeto femenino y su derecho fundamental autónomo, el cual le es intrínseco y cuyo ejercicio, por lo tanto, solo a la mujer compete. 


\section{REFERENCIAS}

Aresti, L. La violencia impune. Una mirada sobre la violencia sexual contra la mujer. México: Universidad Autónoma de Nuevo León, 1997, 39-49.

Ávila, R. El neoconstitucionalismo andino. Quito: Universidad Andina Simón Bolívar, 2016.

Bott, S.; Guedes, A. y Adams, J. Violencia contra las mujeres en América Latina y el Caribe. Análisis comparativo de datos poblacionales de 12 países. Washington, D.C.: Organización Panamericana de la Salud, 2014.

Braidotti, R. Feminismo, diferencia sexual y subjetividad nómade. Barcelona: Gedisa, 2004.

CARBonel, M. Introducción al control de convencionalidad. Disponible en: https://www. academia.edu/download/2021959/El_control_de_convencionalidad_y_el_sistema_colombiano.pdf

Carosio, A. Feminismo y cambio social en América Latina y el Caribe. En VAldivieso, M. et al. Feminismo y cambio social en América Latina y el Caribe. Buenos Aires: CLACSO, 2012, 9-18.

Delgado De Smith, Y. El sujeto: los espacios públicos y privados desde el género. En Revista de Estudios Culturales. 1, 2, 2008, 113-126. Disponible en: https://dialnet. unirioja.es/servlet/articulo?codigo $=3987106$

Duque, C.; Chávez, G. y Melo, M. Experiencias en Ecuador: retorno a la democracia y avances en derechos humanos. En Programa Andino de Derechos Humanos (comp.), Defensa de los derechos humanos en América Latina: avances y retrocesos. Quito: Abya-Yala, 2009, 315-428.

EICHLer, M. Feminist Methodology. En Current Sociology. 45, 2, 9-36. Disponible en: http://journals.sagepub.com/doi/metrics/10.1177/001139297045002003\#articleCitati onDownloadContainer

El Universal. Disponible en: https://www.eluniversal.com.mx/articulo/periodismo-dedatos/2015/10/10/58-paises-permiten-interrupcion-legal-del-embarazo-sin

FACiO, A. Cuando el género suena cambios trae (una metodología para el análisis de género del fenómeno legal). San José: ILANud, Programa Mujer, Justicia y Género, 1992.

Facio, A. Metodología de Género para el Análisis del Fenómeno Legal. En Ávila, R.; Salgado, J. y Valladares, L. (comps.), El género en el derecho. Ensayos críticos. Quito: Ministerio de Justicia y Derechos Humanos, 2009, 181-224.

Ferrajoli, L. Derechos y garantías: la ley del más débil. Madrid: Trotta, 2006.

Galtung, J. Paz por medios pacíficos. Paz y conflicto, desarrollo y civilización. Bilbao: BAKEAZ, 2003.

Hernández, I. Principio de igualdad y violencia de género. En Cuesta, V. y Santana, D. (eds.), Estado de derecho y discriminación por razón de género, orientación e identidad sexual. España: Aranzadi, 2014, 157-205. 
Human Rights Watch. Ecuador: se niega a víctimas de violación sexual la posibilidad de abortos seguros y lícitos. Washington D.C.: Human Rights Watch. Disponible en: https://www.hrw.org/es/news/2013/08/23/ecuador-se-niega-victimas-de-violacionsexual-la-posibilidad-de-abortos-seguros-y

Jaramillo, I. La crítica feminista al derecho. En Ávila, R.; SAlgado, J. y Valladares, L. (comps.), El género en el derecho. Ensayos críticos. Quito: Ministerio de Justicia y Derechos Humanos, 2009, 103-136.

Kane, G.; Galli, B. y Skuster, P. Cuando el aborto es un crimen: la amenaza para mujeres vulnerables en América Latina. $4^{\mathrm{a}}$ ed. Carolina del Norte: Ipas, 2013.

LAMAS, M. Algunas reflexiones relativas al derecho a decidir sobre el propio cuerpo. En Astelarra, J. (coord.), Género y cohesión social. Madrid: Fundación Carolina-Ce ALCI, 2007.

MacKinnon, C. Hacia una teoría feminista del Estado. Madrid: Cátedra, 1995, 23.

MERry, S. Las mujeres, la violencia y el sistema de derechos humanos. En La Ventana, 2002, 15, 64-91. Disponible en: https://dialnet.unirioja.es/servlet/articulo?codigo=5202242

Orias, R. (ed.). El derecho de acceso a la justicia de mujeres. Módulo informativo para operadores judiciales y periodistas. Bolivia: Fundación Construir, 2015.

Ortiz-Prado, E.; Simbaña, K.; Gómez, L.; Stewart-Ibarra, A.; Scott, L. y Cevallos-Sierra, G. Abortion, an increasing public health concern in Ecuador, a 10-year populationbased analysis. En Pragmatic and Observational Research. Dovepress. 2017, 8. 129 135. DOI: https://doi.org/10.2147/POR.s129464. Disponible en: https://www.ncbi.nlm. nih.gov/pmc/articles/PMC5516879/pdf/POR-8-129.pdf

Red de Defensorías de Mujeres de la Federación Iberoamericana del Ombudsman. Debida diligencia en el acceso a la justicia y tutela judicial efectiva de las mujeres víctimas de violencia familiar: alcances, limitaciones y propuestas. Disponible en: http://www. portalfio.org/wp-content/uploads/2015/07/FIO.INF_.0023.2015.pdf

Segato, R. La escritura en el cuerpo de las mujeres asesinadas en Ciudad Juárez. Buenos Aires: Tinta Limón, 2013.

UPRIMNY, R. Las transformaciones constitucionales recientes en América Latina: tendencias y desafíos. En Rodríguez, C. (coord.), Un mapa para el pensamiento jurídico del siglo XXI. Buenos Aires: Siglo XXI Editores, 2011, 109-138.

VAÑó, R. La violencia sexual como crimen de genocidio. Reflexiones en clave de género a propósito del caso Akayesu (Tribunal Penal Internacional para Ruanda). En RevenGA, M. y García, C. (coords.), Decisiones básicas en materia de violaciones de derechos humanos. Madrid: Centro de Estudios Políticos y Constitucionales, 2015, 167-209.

Violencia sexual en Latinoamérica y el Caribe: análisis de datos secundarios. Disponible en: https://clacaidigital.info/handle/123456789/980 


\section{Normatividad nacional, instrumentos y documentos internacionales}

ACNUR. Resolución de la Comisión de Derechos Humanos 2003/45. Disponible en: https:// www.acnur.org/fileadmin/Documentos/BDL/2005/3203.pdf?view=1

Bolivia. Código Penal de 2009. Disponible en: http://www.unodc.org/res/cld/document/ bol/codigo-penal_html/Bolivia_Codigo_Penal.pdf

Bolivia. Constitución Política. Disponible en: http://www.wipo.int/edocs/lexdocs/laws/ es/bo/bo033es.pdf

Bolivia. Ley del Código de Procedimiento Penal. Disponible en: http://www.derechoteca. com/gacetabolivia/ley-no-586-del-30-de-octubre-de-2014/

CEDAW. Recomendación General n. ${ }^{\circ} 19$ adoptada por el Comité para la Eliminación de la Discriminación contra la Mujer. Disponible en: https://tbinternet.ohchr.org/Treaties/ CEDAW/Shared\%20Documents/1_Global/INT_CEDAW _GEC_3731_S.pdf

CIDH. Declaración Conjunta de las Relatoras Especiales sobre los Derechos de la Mujer. Disponible en: https://www.cidh.oas.org/declaracion.mujer.htm

CIDH. Estándares jurídicos vinculados a la igualdad de género y a los derechos de las mujeres en el Sistema Interamericano de Derechos Humanos: desarrollo y aplicación. Actualización del 2011-2014. Bolivia: Fundación Construir, 2015. Disponible en: http:// www.oas.org/es/cidh/informes/pdfs/EstandaresJuridicos.pdf

Colombia. Código Penal. Ley 599 de 2000. Disponible en: http://www.wipo.int/edocs/ lexdocs/laws/es/co/co028es.pdf

Ecuador. Código Orgánico Integral Penal. Disponible en: https://tbinternet.ohchr.org/ Treaties/CEDAW/Shared\%20Documents/ECU/INT _CEDAW _ARL_ECU _18950_S.pdf

Ecuador. Constitución de la República de Ecuador. Disponible en: https://www.oas.org/ juridico/pdfs/mesicic4_ecu_const.pdf

OEA. Convención Interamericana para Prevenir, Sancionar y Erradicar la Violencia contra la Mujer, Belem do Pará. Disponible en: https://www.oas.org/es/mesecvi/docs/ BelemDoPara-ESPANOL.pdf

OHCHR. Herramienta para la incorporación del enfoque de derechos humanos y la perspectiva de género en la elaboración de sentencias relativas a delitos de femicidio y otras formas de violencia contra la mujer. Oficina del Alto Comisionado de Naciones Unidas. Disponible en: https://www.ohchr.org/Documents/Issues/Women/wrGs/Herramienta_DHVSG_alta.pdf

oms. Violencia contra la mujer. Disponible en: https://www.who.int/es/news-room/factsheets/detail/violence-against-women

ONU. Asamblea General. Convención Interamericana para Prevenir, Sancionar y Erradicar la Violencia contra la Mujer. Naciones Unidas. Agosto de 1994. Disponible en: http:// www.oas.org/juridico/spanish/tratados/a-61.html 
ONU. Asamblea General. Convención sobre la Eliminación de Todas las Formas de Discriminación contra la Mujer. Naciones Unidas. Diciembre de 1979. Disponible en: http:// www.un.org/womenwatch/daw/cedaw/text/sconvention.htm

Perú. Código Penal, Decreto Legislativo 635. Disponible en: https://apps.contraloria.gob. pe/unetealcontrol/pdf/07_635.pdf

\section{Jurisprudencia}

Colombia. Corte Constitucional. Sentencia T-988 de 2007. Disponible en: http://www. corteconstitucional.gov.co/relatoria/2007/T-988-07.htm

Colombia. Corte Constitucional, Sala Plena. Sentencia C-355 de 2006. Disponible en: https://www.corteconstitucional.gov.co/relatoria/2006/c-355-06.htm

Corte IDH. Caso Atala Riffo y niñas vs. Chile. Excepción Preliminar, Fondo, Reparaciones y Costas. Sentencia del 24 de febrero de 2012. Disponible en: https://corteidh.or.cr/ docs/casos/articulos/seriec_239_esp.pdf

Corte IDH. Caso de la masacre de las Dos Erres vs. Guatemala. Excepción Preliminar, Fondo, Reparaciones y Costas. Sentencia del 24 de noviembre de 2009. Disponible en: http://www.corteidh.or.cr/cf/jurisprudencia2/ficha_tecnica.cfm?nId_Ficha=361\&lang=es

Corte IDH. Caso de mujeres víctimas de tortura sexual en Atenco vs. México. Excepciones Preliminares, Fondo y Reparaciones. Sentencia de 28 de noviembre 2018. Disponible en: https://www.corteidh.or.cr/docs/casos/articulos/seriec_371_esp.pdf

Corte IDH. Caso Fernández Ortega y otros vs. México. Excepción Preliminar, Fondo, Reparaciones y Costas. Sentencia del 30 de agosto de 2010. Disponible en: http://www. corteidh.or.cr/cf/jurisprudencia2/ficha_tecnica.cfm?nId_Ficha=338\&lang=es

Corte IDH. Caso I.V.vs. Bolivia. Excepciones Preliminares, Fondo, Reparaciones y Costas. Sentencia del 30 de noviembre de 2016. Disponible en:http://www.corteidh.or.cr/docs/ casos/articulos/seriec_329_esp.pdf

Corte IDH. Caso López Soto y otros vs. Venezuela. Excepciones Preliminares, Fondo, Reparaciones y Costas. Sentencia del 26 de septiembre 2018. Disponible en: https:// www.corteidh.or.cr/docs/casos/articulos/seriec_362_esp.pdf

Corte IDH. Caso Rosendo Cantú y otra vs. México. Sentencia de 31 de agosto de 2010. Disponible en: http://www.corteidh.or.cr/CF/jurisprudencia2/ficha_tecnica.cfm?nId_Ficha=339

Ecuador. Corte Constitucional. Sentencia 082-16-SEP-CC. Disponible en: http://portal. corteconstitucional.gob.ec:8494/FichaRelatoria.aspx?numdocumento=082-16-sEP-CC

Perú. Sala Penal Permanente de Huancavelica. Sentencia 2790-2009. Disponible en: https://2019.vlex.com/\#vid/472868106

Perú. Sala Penal Permanente de Lima. Queja 1678-2006. Disponible en: https://www.mpfn. gob.pe/escuela/contenido/actividades/docs/4055_rqueja_001678_2006_princ.acusat. sobreseim.spp_csmc_13.4.07.pdf 